\title{
Wissen auf losen Blättern im Kontext starrer Theorien
}

\section{Theodor Lebers Entzündungsforschung}

\author{
Dorina Stahl
}

\begin{abstract}
Nach zwölf Jahren intensiver Forschung etablierte der Ophthalmologe Theodor Leber (1840-1917) am Ende des 19. Jahrhunderts in der Entzündungsforschung die Chemotaxis der Leukozyten. Obwohl sich seine Theorie damals reibungslos in die immunologische Forschung einschrieb, wird sein Name jedoch bis heute nur in der englischsprachigen Fachliteratur mit der Chemotaxis verknüpft. In seinem Experimentalsystem hatte Leber zwar schon Anfang der 1880er Jahre eine Theorie der chemischen Attraktion der Leukozyten beim Entzündungsprozess entwickeln können. Aber seine unkonventionelle Methodik—die Einführung von chemisch indifferentem Fremdmaterial zur Auslösung einer Entzündung am Kaninchenauge—-widersprach schon vom Ansatz her dem zu diesem Zeitpunkt dominant bakteriologischen Denkstil der Entzündungsforschung. In diesem Forschungsfeld hielt Leber an einer Forschungspraxis fest, die aus einer engen Verzahnung von experimenteller und theoretischer Arbeit bestand. Erst als eine Öffnung des bakteriologischen Denkstils eingetreten war, gelang es Leber seine auf losen Protokollseiten festgehaltenen Versuchsbeobachtungen in überzeugende Belege seiner Entzündungstheorie zu transformieren. Die mikrohistorische Rekonstruktion von Lebers experimenteller und schriftlicher Arbeit anhand seiner Laborprotokolle erschließt die Forschungspraxis eines Wissenschaftlers, der in der damals etablierten mikrobiologischen Entzündungsforschung kaum Anerkennung fand. Durch Verbindung der mikrohistorischen Rekonstruktion mit einer makrohistorischen Analyse lassen sich außerdem Beharrungsfaktoren im Prozess der Wissensentstehung offenlegen. Leber entwickelte eine spezifische Papiertechnik, durch die er seine experimentellen Erkenntnisse zwar mobilisierte und stabilisierte, aber nicht mit dem Fortschreiten der Wissenschaft mithalten konnte.
\end{abstract}

Schlüsse/wörter: Entzündung, Experimentalsystem, Denkstil, Papiertechnik, 19. Jahrhundert

Knowledge on Loose Sheets in the Context of fixed Theories. Theodor Leber's Research of Inflammation

At the end of the nineteenth century, after twelve years of intensive research, the ophthalmologist Theodor Leber (1840-1917) established the chemotaxis of leukocytes as part of inflammation research. Although at the time his theory was smoothly enlisted into immunological research, up until now his name has been connected to chemotaxis only in the English-language literature. Leber was able to use his experimental system to develop a theory of the chemical attraction of the leukocytes during inflammation processes by the beginning of the 1880s, but his unconventional methodology_-introducing chemically neutral contaminants in order to trigger inflammation in the eyes of rabbits-contradicted the basic bacteriological Denkstil (style of thought) of inflammation research at the time. Leber held fast to his research practice, which consisted of closely interlocking experimental and theoretical work. Only when an opening appeared in the bacteriological Denkstil was Leber able to transform his experimental observations, written on loose sheets of paper, into convincing evidence for his theory of inflammation. This microhistorical reconstruction of Leber's experimental and written work, based on his original lab protocols, opens up the research practice of a scientist who was not recognized by the established microbiological inflammation research of 
the time. Moreover, persistent factors in the generation of knowledge are revealed by connecting this microhistorical reconstruction with a macro-history analysis. Indeed Leber developed his specific paper technology in order to mobilise and stabilise the scientific findings gained through experiment because of the persistence of the bacteriological Denkstil.

Keywords: Inflammation, experimental system, style of thought, paper technology, 19th century

\section{Einführung in das wissenschaftshistorische Feld}

Im 19. Jahrhundert entwickelte sich in den Naturwissenschaften und in der Medizin eine ausgeprägte Experimentalkultur der Laborforschung. Wissenschaftshistorisch und -theoretisch wird diese seit über 30 Jahren verstärkt in den Blick genommen. So beschäftigen sich beispielsweise Ian Hacking und Andrew Cunningham mit den Vorgängen im Labor und dem Entstehen von Wissen durch Experimente in den Wissenschaften im 19. Jahrhundert (Hacking 1983; Cunningham 1992). Anhand von Laboraufzeichnungen und ihrem Vergleich mit zeitgenössischen Publikationen wird die Generierung von Wissen aus dem Forschungshandeln der Akteure rekonstruiert, wie es Bruno Latour, Hans-Jörg Rheinberger und Frederic Holmes in verschiedenen Ansätzen entwickelten (Latour 1986; Rheinberger 1993; Holmes 2003). Im Fokus der Wissenschaftsgeschichte standen vor allem Entdeckungen wie die der DNA oder der Tuberkuloseerreger (Rheinberger 2001; Gradmann 2005). Dieser Aufsatz leistet nun einen Beitrag zu diesem Feld anhand der Laborprotokolle des Augenarztes Theodor Leber, die er Ende des 19. Jahrhunderts zur Erforschung der Entzündung anfertigte.

Bei diesen Laborprotokollen handelt sich um ein Konvolut von zu Heften geordneten losen Blättern mit insgesamt 265 beschriebenen Seiten, die der ehemaligen Leiter der Augenklinik der Universität zu Lübeck dem dortigen Institut für Medizingeschichte und Wissenschaftsforschung übergab. ${ }^{1}$ Die Laborprotokolle Lebers dokumentieren nun aber weder eine wissenschaftliche Entdeckung, die eine umfangreiche Rezeption erfuhr, noch eine Errungenschaft, die in der deutschsprachigen Fachliteratur mit dem Namen Lebers besonders verknüpft ist. Die Rekonstruktion von Lebers Forschung anhand originaler Protokolle macht nachvollziehbar, wie Beharrungstendenzen in der Wissenschaft entstehen und wie sie sich auswirken. Auf diese Weise kann gezeigt werden, warum sich Lebers Forschungen lange Zeit kaum veränderten und erst verspätet anerkannt wurden, als sie durch neuere Forschungsergebnisse beinahe als veraltet angesehen werden konnten.

Theodor Leber war nach Ende des Studiums und nach Lehrjahren in Wien, Paris und Berlin zunächst Direktor der Augenklinik an der Universität Göttingen (1870-1890) und anschließend in Heidelberg (1890-1910). ${ }^{2}$ Neben seiner klinischen und akademischen Tätigkeit führte er Graefes Archiv für 
Augenheilkunde als Herausgeber fort. In der Augenheilkunde konnte er sich als Vorreiter der experimentellen Ophthalmologie und Entdecker seltener angeborener Sehstörungen einen Namen machen. Seit Ende der 1870er Jahre beschäftigte sich Leber intensiv mit den biologischen Vorgängen bei der Entzündung. Während auf dem Höhepunkt der mikrobiologischen Revolution das Entzündungsgeschehen vor allem als Folge des Angriffs pathogener Keime diskutiert wurde, vertrat Leber die Ansicht, dass der Entzündungsvorgang zur Beseitigung der schädigenden Substanz und zur Wiederherstellung der Integrität des Gewebes diene (vgl. Canguilhem 1979: 211; Sarasin 2001: 319).

Wichtige Vermittler des Entzündungsgeschehens waren, laut Leber, die Leukozyten. So führte er 1888 die chemische Anlockung der weißen Blutkörperchen zum Entzündungsherd, die sogenannte Chemotaxis, als grundlegenden Mechanismus des Entzündungsprozesses in die Medizin ein. Der starre Denkstil der Bakteriologen, auf den schon Ludwig Fleck in seinem Buch Die Entstehung einer wissenschaftlichen Tatsache hingewiesen hat, wie auch Lebers Randstellung im Entzündungsdiskurs führten dazu, dass seine Entdeckungen zunächst wenig Beachtung fanden (Fleck 1980: 122). Sein wichtiger Aufsatz aus dem Jahr 1888 wurde schlicht nicht wahrgenommen. Leber erreichte erst mit seiner Monographie Die Entstehung der Entzündung Aufmerksamkeit, da die hier formulierte Vorstellung eher zum neuen Denkstil der immunologisch orientierten Wissenschaften passte. Die physiologischen Abwehrreaktionen des Organismus auf eingedrungene Fremdstoffe oder Mikroorganismen standen nun im Fokus der Untersuchungen. ${ }^{3}$

Lebers retrospektiv eigentlich als progressiv zu beurteilendes Vorgehen Ende der 1870er Jahre wurde also über die lange Dauer seiner stereotyp fortgesetzten Forschungen von den Fortschritten in der wissenschaftlichen Entzündungsdebatte eingeholt und schließlich überrollt. Zudem beschränkten sich seine Publikationen und die Leserschaft seiner veröffentlichten Erkenntnisse auf den peripheren Kreis der zur Entzündung Forschenden.

Im Folgenden soll die bisher nur knapp skizzierte Karriere von Lebers Entzündungsforschung aus den von Leber angefertigten Laborprotokollen rekonstruiert werden, um auf diese Weise herauszuarbeiten, wie die öffentliche Wissenschaftsentwicklung sich auf die individuelle Forschung auswirken kann und welche Beharrungsfaktoren dabei auftreten können. Anhand der von Leber angefertigten Laborprotokolle werde ich in den folgenden beiden Abschnitten schrittweise ermitteln, wie ein zunächst zufällig beobachtetes Phänomen allmählich als Chemotaxis der Leukozyten zum Gegenstand experimenteller Untersuchung avancierte und als solcher stabilisiert wurde, bis er als wesentlicher Teil des Entzündungsprozesses in die Medizin Eingang fand.

Dabei können mindestens fünf Bearbeitungsschritte im Medium der schriftlichen Darstellung unterschieden werden. Mit Hilfe von diesen fünf 
schriftlichen Techniken (Verschriftlichen, Sammeln, Vergleichen, Überarbeiten, Gruppieren) erreichte Leber eine Transformation seiner experimentellen Beobachtungen zu Belegen seiner Entzündungstheorie: Diese Rekonstruktion von Lebers Forschungspraxis kann exemplarisch verdeutlichen, wie das Aufschreiben, Sammeln und Ordnen experimenteller Beobachtungen epistemische Funktionen gewinnt und neues Wissen generiert. Dafür orientiert sich diese Analyse an neueren Ansätzen zum Schreiben und Zeichnen als Verfahren: an der von Volker Hess und Andrew Mendelsohn geprägten Papiertechnik (Hess \& Mendelsohn 2010; 2013: 1-10) wie auch an Bruno Latours Konzept des immutable mobile (Hoffmann 2008; Latour 1990: 19-68).

Die Papiertechnik Lebers gilt es in den historischen Kontext einzuordnen, um Mechanismen in der Wissensentstehung und Anerkennung zu erschließen. Die Entzündungsforschung Ende des 19. Jahrhundert wird dafür mit Ludwig Flecks Lehre vom Denkstil und Denkkollektiv näher betrachtet (vgl. Fleck 1980). Damit kann aufgezeigt werden, welche Bedingungen zum Ausgang des Jahrhunderts in der Wissenschaft vorherrschten, die die Entwicklung einer wissenschaftlichen Tatsache von der Erkenntnis im Labor bis zu ihrer Anerkennung in der Wissenschaft beeinflussten.

\section{Lebers experimentelle Praxis im historischen Kontext}

Lebers Entzündungsforschung begann 1879, als er in seiner Augenklinik in Göttingen einen Patienten mit einer Pilzinfektion an der Cornea (Hornhaut) behandelte (Leber 1879: 285-301). Da in der Wissenschaft bisher nicht bekannt war, dass Aspergillen pathogen wirkten, stellte Leber weitere Versuche an (Soyka 1878: 131f.). Ihm war daran gelegen, den Mechanismus der Entzündungsreaktion des Körpers näher zu ergründen. Nicht nur intakte Mikroorganismen, sondern auch deren Bestandteile riefen eine Entzündung hervor. Er vermutete daraufhin ein chemisches Wirkungsprinzip, nach dem er zu suchen begann. Gewissermaßen im Ausschlussverfahren verwendete er in seinen ersten Versuchen chemisch indifferente Fremdkörper, die überraschenderweise entzündliche Veränderungen im Augengewebe auslösten, womit sich ihm ein ganz neues Forschungsfeld eröffnete. Im Sinne Hans-Jörg Rheinbergers entwickelt sich Lebers Experimentalsystem durch diesen Zufall: Der als „technisches Ding“ eingesetzte Fremdkörper gewann durch die unerwartete Gewebsreaktion, die er verursachte, eine epistemische Dimension (Rheinberger 2001: 25).

Leber verfolgte damit einen Forschungsansatz, der sich von den damals dominanten Herangehensweisen zur Erforschung der Entzündung deutlich unterschied. Denn nach der Entdeckung, dass Mikroorganismen wie Bakterien 
eine Entzündung auslösten (Grawitz \& de Bary 1887: 67), galt als sicher, dass das Entzündungsgeschehen lediglich die Folge ihres Eindringens und Angriffs ist. Lebers Hypothese einer chemischen Ursache wurde daher 1881 auf dem internationalen Medizinkongress in London von anderen Teilnehmern wie den bekannten Ophthalmologen Johann Friedrich Horner (1831-1886) und Hermann Knapp (1832-1911) als Randerscheinung abgetan (Mac Cormac 1881), ebenso von Rudolf Virchow (1821-1902), einem auf dem Gebiet der Entzündungsforschung versierten Pathologen.

Die damals die Medizin beherrschende bakteriologische Forschung beschrieb Fleck aus seiner eigenen historischen Perspektive als starren Denkstil (Fleck 1980: 122). Fleck umfasste mit seinem Begriff Denkstil ein Festhalten an bestimmten Vorstellungen, die die eigenen Experimente und die Deutung der Beobachtungen beeinflussen (Fleck 1980: 85). Abhängigkeiten der Dominanz eines Denkstils seien Erfolg, Praxisbezug und Persönlichkeit, die sich unter der bakteriologischen Forschung von Robert Koch (1843-1910) und Louis Pasteur (1822-1895) besonders hervorgetan hätten (Fleck 1980: 22).

Leber verfolgte, weitgehend unberührt von der wissenschaftlichen Öffentlichkeit, im Labor weiter die unerwartete entzündliche Reaktion auf chemisch indifferente Fremdkörper. Bedingung für seine Hypothese war eine aseptische Umgebung. Leber setzte Fremdkörper aus verschiedenen Materialien wie Gold, Silber und Glas als chemische Reize in parallelen Versuchsreihen ein, um die Reaktionen beobachten und miteinander vergleichen zu können. Dabei offenbarten sich Differenzen im Entzündungsverhalten. Es zeigten sich bei den verschiedenen Materialien Unterschiede in der Intensität und auch ausbleibende Reaktionen, sodass die Versuchsreihen fortgesetzt, abgebrochen und neue angesetzt wurden. ${ }^{4}$ Insgesamt wurde Lebers Experimentalsystem so über die Jahre am Laufen gehalten (Rheinberger 2001: 76-87). Lebers Versuchsablauf war bestimmt von zeitlich eng getakteten makroskopischen Beobachtungen, die sich nach Tötung des Versuchstieres auf die histologische Untersuchung des frisch herausgenommenen oder haltbar gemachten Augapfels verlagerten. Die histologischen Beobachtungen waren für Leber von besonderer Relevanz, da hier die Entzündungsprozesse bis auf die Zellebene verfolgt werden konnten. Seine Annahme einer chemischen Wirkung im Entzündungsprozess testete Leber in einer zweiten Versuchsphase ab 1883, indem er das Fremdmaterial in fein gemahlener Form injizierte, womit er die Konzentration des Fremdstoffs steigerte. ${ }^{5}$ Durch die erhöhte Konzentration des Fremdstoffs sollte eine stärkere Entzündung ausgelöst werden. Leber beobachtete bei seiner neuen Versuchsreihe tatsächlich ein vermehrtes Auftreten der Leukozyten (Cohnheim 1914). ${ }^{6}$ Zudem beschrieb er in seinen Protokollen das Vorkommen von Goldkörnchen innerhalb der „Entzündungszellen“?

Mit dieser Beobachtung knüpfte er an die Veröffentlichungen des Zoologen Ilias Metschnikoff (1845-1916) an. Dieser hatte 1883 herausgefunden, 
dass Leukozyten Bakterien beseitigen konnten, indem sie diese in sich aufnahmen. Er nannte den Mechanismus "Phagozytose" und führte die Vorstellung eines natürlichen Abwehrprozesses in den Entzündungsdiskurs ein (Metschnikoff 1883: 1-28; 1884: 177-195). In den 1880er Jahren wurde Metschnikoffs Theorie jedoch nur vereinzelt aufgegriffen. Erst ab 1890 mehrten sich Veröffentlichungen, die sich seiner Theorie einer natürlichen Abwehr anschlossen. Ab 1883 baute Leber seine Experimente mit einem neuen „technischen Ding“ (Rheinberger 2001: 25), in Form eines halbgeschlossenen Glasröhrchens, weiter aus. Laut seiner Protokollführung wollte er damit herausfinden, ob auch das im Glasröhrchen eingeschlossene Fremdmaterial noch eine Auswanderung der Leukozyten verursachen könne. ${ }^{8}$ Leber gelang es mit diesem Aufbau, die gezielte Wanderung der Leukozyten zum Fremdmaterial und dessen Aufnahme zu erkennen. Er hatte sein Experimentalsystem so verdichtet, dass er die Chemotaxis der Leukozyten belegen konnte. Das Jahr 1883 markiert also einen Wendepunkt in der experimentellen Praxis Lebers, da sich seine nachfolgenden Versuche auf diese Theorie der chemischen Attraktion hin ausrichteten.

Am öffentlichen Diskurs beteiligte sich Leber damit zunächst nicht. 1884 publizierte er lediglich einige praktische Ratschläge für Augenärzte zum Umgang mit Fremdmaterial im Auge (Leber 1884: 243-258). Über die Gründe, warum Leber seine neue Theorie der chemischen Attraktion der Leukozyten zu dem Zeitpunkt nicht publizierte, lässt sich nur spekulieren. Vermutlich war ihm durch seine vorherigen öffentlichen Auftritte bewusst geworden, dass sich der Wissenschaftsdiskurs vordergründig auf die bakteriologische Forschung konzentrierte. Vielleicht befürchtete er, mit seinen Erkenntnissen wenig Gehör zu finden, was auch die geringe Wahrnehmung von Metschnikoffs Theorie zu derselben Zeit vermuten lassen würde. Leber fokussierte sich aber weiterhin auf seine Versuchsbeobachtungen in gezielt wiederholten Versuchsreihen, die sich erst nach einer gewissen Anzahl von Wiederholungen zunehmend stabilisierten. ${ }^{9}$

Die Protokollführung verweist darauf, dass er den Erkenntnisgewinn aus seinen Experimenten sehr genau nahm. Das verdeutlichen einerseits die nahezu täglichen Einträge und andererseits die Dauer der einzelnen Versuche, die sich über Wochen und zum Teil Jahre erstreckten, um auch eine längere Fremdkörpereinwirkung genau zu untersuchen. Folglich stellte er der wissenschaftlichen Öffentlichkeit seine Sichtweise der Entzündung als nützlichen Vorgang, der zur Beseitigung einer schädigenden Substanz diente, erst 1888 in einem Aufsatz vor und rückte das von ihm als „Chemotaxis“ bezeichnete Phänomen als entscheidendes Wirkprinzip ins Zentrum seiner Entzündungstheorie (Leber 1888: 460-464; 1889: 192-194). Allerdings finden sich keine Rezeptionen dieses Artikels aus der damaligen Zeit. Lebers Theorie scheint noch zu weit entfernt von den wissenschaftlichen Auffassungen und 
Annahmen im Denkkollektiv gewesen zu sein. Als Ophthalmologe stand Leber auch abseits des inneren Kreises der Entzündungsforscher.

Diese fehlende Resonanz führte ihn erneut zurück ins Labor. Er nahm sich nun Präparate von bereits makroskopisch untersuchten Augen aus früheren Versuchsserien vor, die in Fixierflüssigkeit und Einbettungsverfahren haltbar gemacht worden waren. Mit der nachträglichen histologischen Untersuchung produzierte Leber weitere Belege für seine Entzündungstheorie. Anhand der Protokolleinträge zwischen 1888 und 1891 lässt sich nachvollziehen, dass sich Leber insbesondere für Zellformen und Bindegewebsreaktionen interessierte, die in den Einträgen aus den Jahren zuvor nur eine untergeordnete Rolle gespielt hatten, aber nun in der zweiten Beobachtungsstufe diese Protokolle dominierten. ${ }^{10}$ Anhand der beobachteten Phagozytose und Abkapslungsvorgängen festigte sich seine Theorie von der Abwehr des Organismus gegen Fremdkörper durch die gezielt angelockten Leukozyten. Mit seinen histologischen Untersuchungen zur Beteiligung der Leukozyten an der Proliferation des Gewebes und damit an den Regenerationsvorgängen in der Entzündung konnte Leber an eine breite Diskussion in der Wissenschaft anschließen (Leber 1891: 496; Karg 1887: 323-336). Seine nachträgliche Untersuchung alter Präparate wie auch seine Rückkehr ins Labor für zahlreiche Versuchswiederholungen erscheinen als Stabilisierungsstrategien, um seine Erkenntnisse in das neu entstehende immunologische Denkkollektiv einbringen zu können.

Anders als die öffentliche Entzündungsdebatte, die sich ab 1850 bis ins 20. Jahrhundert hinein nach den vorherrschenden Meinungen ausrichtete, wie ein zeitgenössischer Leipziger Chirurg die damalige Entzündungsforschung einmal charakterisierte (Karg 1887: 323), hielt Leber an seinem Experimentalsystem fest. Weil in den 1880er Jahren bakteriologische Erkenntnisse die Entzündungsdebatte bestimmten und andere Ansichten mehr in den Hintergrund drängten, erschwerten es diese Rahmenbedingungen Leber, seine experimentell gewonnenen Erkenntnisse einzubringen.

\section{Beschreibung des Quellenmaterials}

Im Abgleich mit einigen seiner Autographen konnte die Handschrift der Protokollsammlung eindeutig Leber zugeordnet werden. ${ }^{11}$ Die Protokolle beschreiben fortlaufend verschiedene Versuchsserien und stehen inhaltlich in engem Bezug zu Lebers Monographie Die Entstehung der Entzündung (1891). Dort geht Leber detailliert auf seine Entzündungsversuche ein und erläutert seine Entzündungstheorie ausgehend von Beschreibungen der Effekte von Injektionen unterschiedlicher Stoffe in Kaninchenaugen. Er beschreibt Versuchsreihen mit Injektionen von Metallen, verschiedenen Säuren sowie Bakterienbestandteilen, die seine umfangreiche Forschung zur Entzündung 
belegen. ${ }^{12}$ Die Protokollsammlung hingegen umfasst nur die Injektionsversuche mit chemisch indifferentem Material wie Gold, Silber, Glas oder Platinschwarz, wobei sich mehrere der Versuchsprotokolle mit Versuchsbeschreibungen in der Monographie decken. ${ }^{13}$

Die Protokolle befanden sich in einem Pappkarton. Sie lagen dort als lose Blätter, jeweils mit einem Blatt Papier umschlagen zu 16 Heften gebündelt. Auf dem Umschlag eines jeden Heftes ist Material und Ort der Injektion notiert. Die vorgefundene Reihenfolge der Hefte wurde beibehalten und von 1 bis 16 von mir durchnummeriert. Innerhalb eines Heftes findet sich oft ein Durcheinander von Versuchsnummerierungen mit arabischen als auch lateinischen Ziffern. Es lässt sich hier keine Chronologie der Versuche nachvollziehen. Teilweise kommen Nummerierungen doppelt vor, in vereinzelten Nummernfolgen fallen Lücken auf und innerhalb des Protokolltextes wird Bezug auf Versuche genommen, die sich nicht in der vorliegenden Sammlung befinden. Hinter dieser scheinbaren Unordnung verbirgt sich - wie im Folgenden noch erläutert werden soll - ein ordnender Arbeitsschritt, bei dem die Protokolle aus ihrem zeitlich nummerischen in einen systematischen Zusammenhang umgruppiert werden. Doch nahezu alle Protokolle sind nach dem gleichen Schema aufgebaut (vgl. Abb. 1 und 2).

So ist die erste Seite mit der Versuchsnummer und der Jahreszahl des Versuchsbeginns betitelt. Es folgt eine knappe Beschreibung des verwendeten Fremdmaterials und des Injektionsortes im Auge mit einer Beschreibung des Versuchstiers. Linksbündig steht das Datum des Protokolleintrages und es folgen teils stichwortartig, teils ausformuliert die Versuchsbeobachtungen. Zunächst sind es makroskopische Beschreibungen und im Verlauf des Versuches schließen sich je nach Auftreten einer Entzündungsreaktion mikroskopische Untersuchungen frisch enukleierter (Entfernung des Augapfels aus der Augenhöhle) oder fixierter und eingebetteter (histologische Verfahren zur Herstellung der Haltbarkeit und Schneidfähigkeit) Versuchsaugen an. Der Versuchsaufbau und seine Durchführung sind jeweils nur kurz skizziert, während vor allem die mikroskopischen Untersuchungen ausführlich beschrieben sind. Die Einträge enthalten sachliche Beschreibungen der sichtbaren Entzündungsprozesse, der Veränderungen des umgebenden Gewebes und des Fremdkörpers. An einigen Stellen finden sich Deutungen des Gesehenen. ${ }^{14}$

Die meisten der in den Protokollen dokumentierten Experimente beinhalteten die Injektion von Gold in verschiedene Strukturen der Kaninchenaugen. ${ }^{15}$ Es fällt auf, dass für mehrere Versuche identisches Fremdmaterial verwendet wurde. Es handelte sich also um sorgfältig geplante Versuchsreihen. ${ }^{16}$ Die notierten Jahreszahlen auf den Protokollen lassen zudem erkennen, dass verschiedene Versuchsphasen bestanden, in denen einzelne Versuchsreihen auch noch nach drei Jahren wiederholt werden konnten. Versucht man über die Ordnung der Hefte hinweg die 
Jahreszahl

Versuchsnummer
Tag der Enukleation

Todesdatum

Tage bis zur Enukleation

Beschreibung Versuchsaufbau und Versuchstier ggf. Materialherstellung

Datum Makroskopische Beobachtung

Datum R.A. Geringe Inject., Trübung im Stichkanal (typisches Beispiel)

Datum

Datum

Datum Enukleation ggf. Beschreibung des Fixierverfahren

Datum Anatomische Untersuchung

Datum mikroskopische Beschreibung

\section{Datum Vers. beendigt, Reste entfemt (typisches Ende)}

Abb. 1 Schema eines Versuchsprotokolls (eigene Darstellung)

Versuchsprotokolle chronologisch zu verfolgen, wird zwar deutlich, dass Versuchsreihen mit der Injektion verschiedener Materialien oft parallel liefen, doch bauten sie weder aufeinander auf, noch waren sie vollständig. Die Protokolle enthalten Einträge mit großen zeitlichen Abständen. So begann beispielsweise ein Versuch über die Injektion eines Glassplitters ins Auge eines Kaninchen im Oktober 1879, wurde im Dezember des Jahres unterbrochen und von April 1880 bis Januar 1882 fortgesetzt, bis das Kaninchen verstarb. Erst im Juni 1889 wurde der Versuch mit der histologischen Untersuchung wieder aufgenommen, im Oktober 1900 das Vorhandensein der histologischen Präparate vermerkt und schließlich im April 1916 die Beseitigung der Versuchsreste notiert. Unter den Protokollen finden sich Versuchsreihen, die in die Monographie von 1891 einflossen, aber auch zwei Hefte, die Versuchsreihen von 1892 und 1897 beschreiben, als Leber nochmals mehrere Serien nahezu identischer Versuche unternahm.

Es handelt sich bei der Protokollsammlung also um einen vielschichtig erstellten Arbeitsapparat, der Lebers langjährige Versuchsserien umfasst, seine umfangreiche Forschung zur Entzündung in ihren Einzelheiten 


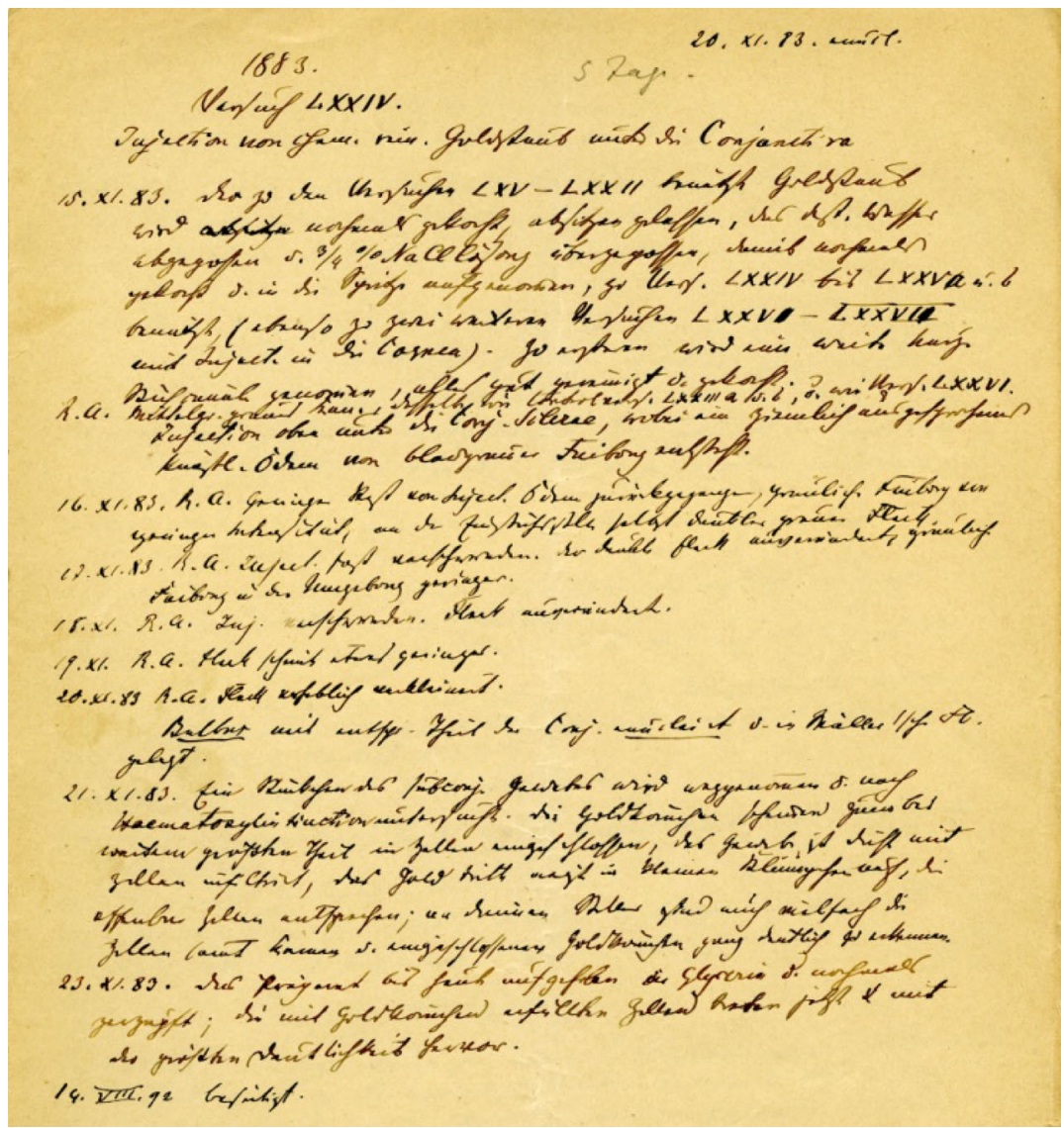

Abb. 2 Beispielseite eines Versuchsprotokolls aus Heft 2, Versuch LXXIV, aus dem Jahr 1883 über die Injektion von Goldstaub unter die Konjunktiva (Bindehaut)

verdeutlicht und seine nach Abschluss der publizierten Monographie fortgeführte Entzündungsforschung unterstützt. Demnach entspricht die Protokollsammlung auch nicht dem Format eines festgebundenen Laborbuches, in das linear und chronologisch eingetragen wurde. Die losen Blätter weisen vielmehr eine Ordnung ganz eigenen Charakters auf, wie im Folgenden spezifiziert wird.

\section{Ordnung und Analyse der schriftlichen Techniken innerhalb der Protokollsammlung}

Erst bei genauerer Betrachtung und im Vergleich mit der Monographie wird die Ordnung der Protokolle nachvollziehbar. Den Schlüssel dazu liefern die Versuchsprotokolle eines Heftes, die sich eins zu eins mit Versuchen eines 
Kapitels in der Monographie decken. ${ }^{17}$ Dort wurden verschiedene Versuchsprotokolle aus der Sammlung nahezu wörtlich übernommen und die Entzündungstheorie dazu erläutert. Es kann daher angenommen werden, dass die gefundene Protokollsammlung mit ihren Heften eine gezielte Zusammenstellung von Protokollen aus einem umfangreicheren Forschungsmaterial darstellt, das als Vorlage für die Argumentation in der Monographie verwendet wurde. Innerhalb der Monographie haben die Versuchsbeschreibungen, die auch dort in Form von Protokollen verfasst sind, die Funktion, die Entzündungstheorie zu belegen und zu veranschaulichen. So wird die Arbeit im Labor einerseits nachgestellt und andererseits aus den Versuchsbeobachtungen ein Beleg für die Theorie der Entzündungsvorgänge entwickelt.

Die schematische und sorgfältige Führung der Protokolle, der große zeitliche Rahmen der Protokolleinträge und verschiedene Überarbeitungsformen wie Unterstreichungen, Korrekturen oder Ergänzungen belegen darüber hinaus, dass das Schreiben der Protokolle, ihre Sortierung und die nachträgliche Bearbeitung wichtige Arbeitsschritte und damit ein wesentlicher Bestandteil von Lebers Experimentalsystem waren.

Christoph Hoffmann hat anhand von Sektionsprotokollen das prozedurale und epistemische Aspekte des Schreibvorganges näher herausgearbeitet (Hoffman 2008). Daran anknüpfend kann Lebers Schreibarbeit in fünf epistemisch relevante schriftliche Verfahrensschritte zergliedert werden, die deutlich machen, wie das Schreiben zur Forschungspraxis Lebers gehört (Rheinberger 2005: 343-356).

\section{Verschriftlichen}

Den Ausgangspunkt bilden die Verschriftlichungen der Versuchsbeobachtungen am Tier bzw. unter dem Mikroskop. Da der Hauptanteil der Protokolleinträge sich auf mikroskopische Beobachtungen konzentriert, tritt damit das Festhalten der Beobachtungen der zellulären Prozesse als wesentliches Anliegen des Protokollierens hervor. Das Aufschreiben der experimentellen Beobachtungen fixierte auf Papier Prozesse, etwa die Rötung der Bindehaut oder eine Anhäufung von Zellen um den Fremdkörper, die nur kurzzeitig sichtbar waren, aber für ein Entzündungsgeschehen sprachen. In der Terminologie Bruno Latours wurden die Beobachtungen damit in immutable mobiles transformiert (Latour 1990: 19). Leber war es nun bei der Weiterführung eines Experiments möglich, zu vorherigen Prozessen zurückkehren. Die biologisch angelegte Flüchtigkeit von Lebensprozessen wurde durch die schriftliche Fixierung greifbarer und konnte in die weitere Forschungsarbeit einfließen. Die Protokolle dienten aber auch schlicht der Dokumentation des Versuchsablaufs, da Leber die Vorbereitung und Injektion des Fremdmaterials meist von Assistenten durchführen ließ und an diesen Schritten zu Versuchsbeginn nicht beteiligt war. ${ }^{18}$ Im Detail betrachtet, zeigt die Protokollsammlung einige weitere Besonderheiten, die die Eigenart der 


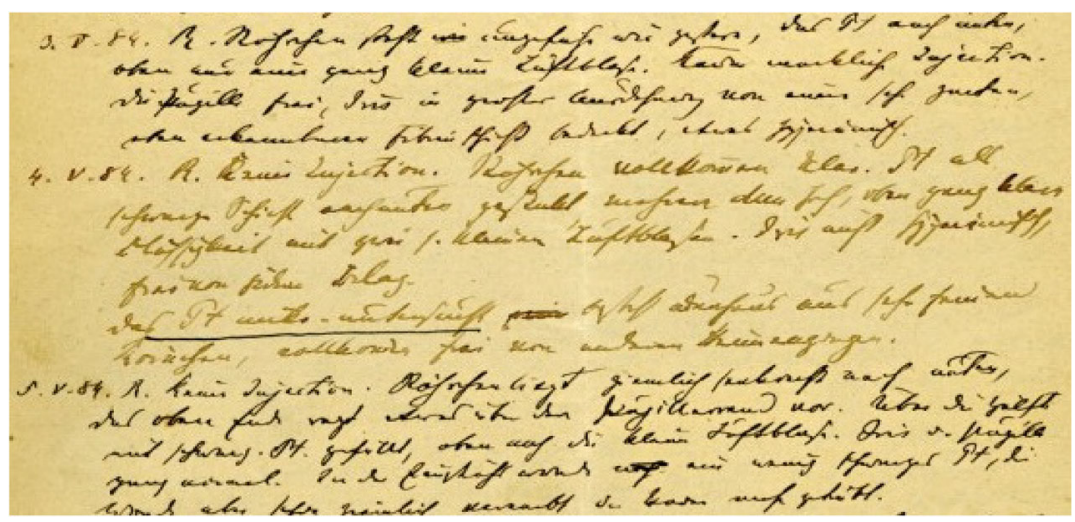

Abb. 3 Ausschnitt eines Protokolls aus Heft 15, versuch 16, aus dem Jahr 1884 über die Injektion von Platinschwarz im Röhrchen in die vordere Augenkammer. Am 4.5. findet sich eine andere Tintenfärbung und Auftragungsdicke als an den anderen Tagen

Verschriftlichung von Lebers Beobachtungen veranschaulichen. So fällt unter den Notizen auf, dass Einträge eine unterschiedliche Tintenfärbungen und Auftragungsdicke aufweisen (vgl. Abb. 3).

Abbildung 3 zeigt, dass das Datum „3.V.84“ in der gleichen Tintenfärbung geschrieben wurde wie Datum und Eintrag am nächsten Tag. Auch die Unterstreichung weist eine andere Tintenfärbung auf, wie der Eintrag am „4.V.84". Leber schrieb und überarbeitete seine Einträge also zu unterschiedlichen Zeitpunkten und nicht in einem Fluss. Die vollständig ausformulierten Sätze in zumeist sehr sauberer Schrift ohne stenographische Elemente weisen zudem darauf hin, dass das Aufschreiben vermutlich nicht direkt am Versuchstisch im Labor entstand. Die Abbildung 4 kann die flexible zeitliche Protokollierung verdeutlichen.

Eine Woche nach dem Eintrag vom „8.VII.89“ wurde das Protokoll mit einem neuen Datumseintrag „15.VII.89“ fortgeführt. Jedoch handelte es sich inhaltlich um eine Fortsetzung der alten Beobachtung, sodass das Datum mit einem Tintenstrich zu einem späteren Absatz versetzt wurde. Wann genau die Einträge erfolgten, lässt sich im Einzelnen nicht rekonstruieren. Jedoch fanden sie wahrscheinlich zeitnah $\mathrm{zu}$ den jeweiligen Versuchsschritten statt. Zumindest an der Abbildung 5 lässt sich rekonstruieren, dass der Eintrag am gleichen Versuchstag vorgenommen wurde.

Abbildung 5 zeigt, dass der Beginn des Versuchsprotokolls auf ein neues Papier geklebt wurde. Der Versuchsplan wurde hier geändert. Denn die am „20.XI.83“ geplante Enukleation des Auges wurde doch nicht durchgeführt, sondern der Versuch fortgesetzt. Die Änderung lässt sich an dem durchgestrichenen Datum am oberen Rand des Bogens nachvollziehen. Die Rekonstruktion der verschiedenen zeitlichen Phasen des Aufschreibens zeigt an dieser Stelle, dass die vorgefundenen Protokolle zwar wie typische 


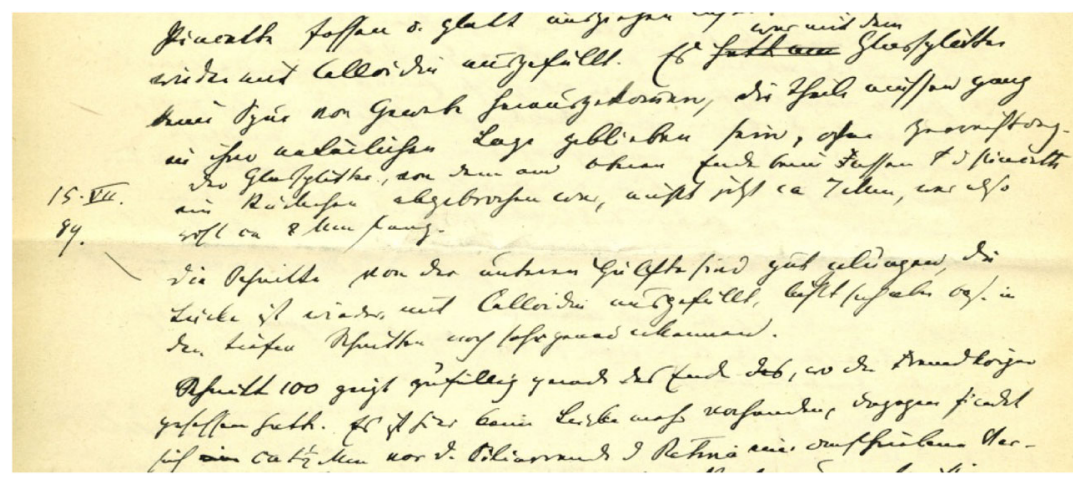

Abb. 4 Ausschnitt des Protokolls aus Heft 7, Versuch XXXV a, aus dem Jahr 1879 über Glassplitter im Glaskörper. Oberer Bildabschnitt ist ein Eintrag vom 8.VII.1889

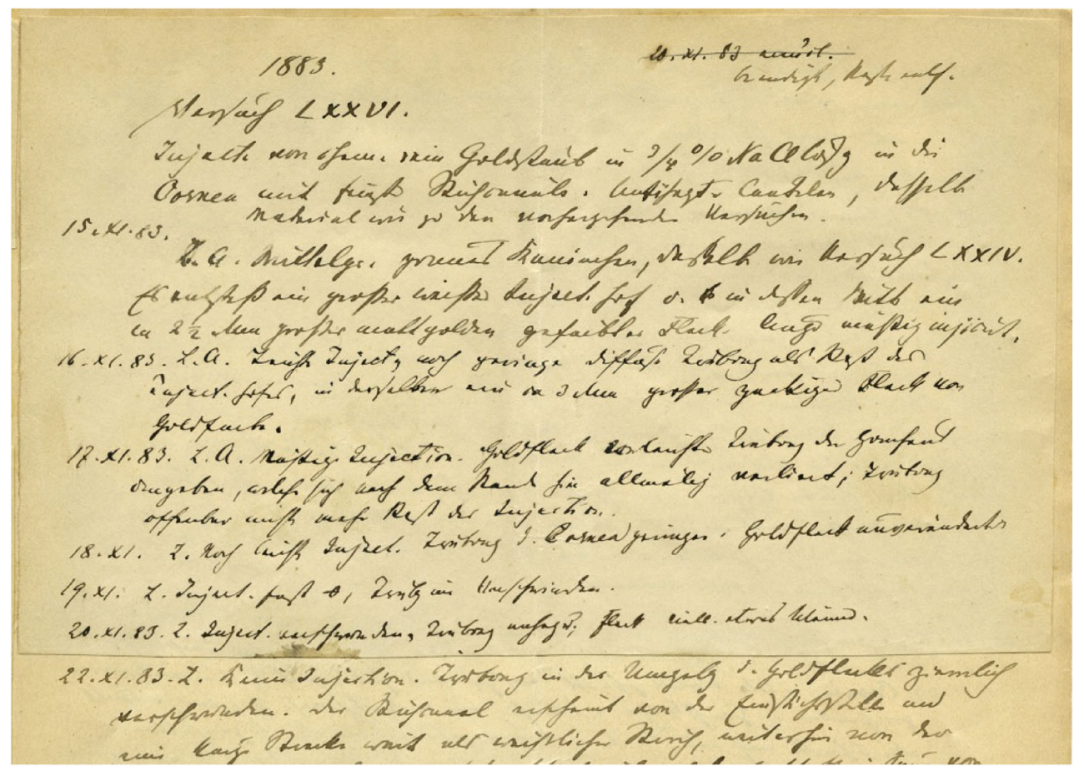

Abb. 5 Ausschnitt aus Heft 6, Versuch LXXVI, aus dem Jahr 1883 über die Injektion von Goldstaub in die Cornea. Die ersten Protokolleinträge wurden auf ein neues Blatt Papier geklebt, die zunächst oben notierte, für den 20.XI.83 geplante Enukleation verschoben. Dann wurde dieser Eintrag durchgestrichen und stattdessen notiert „,beendigt, Reste entf"

Versuchsprotokollierungen aussehen, aber nicht den gleichen Entstehungsprozess wie Versuchsaufzeichnungen aus Laborbüchern haben, die parallel zu der experimentellen Arbeit angefertigt werden. Dass es sich bei den Notizen der Versuchsbeobachtungen zudem um sorgfältig überlegte Formulierungen handelte, deutet nicht nur die saubere und ordentliche Schriftführung an, sondern auch gelegentlich in den Text integrierte Skizzen. An der Abbildung 6 


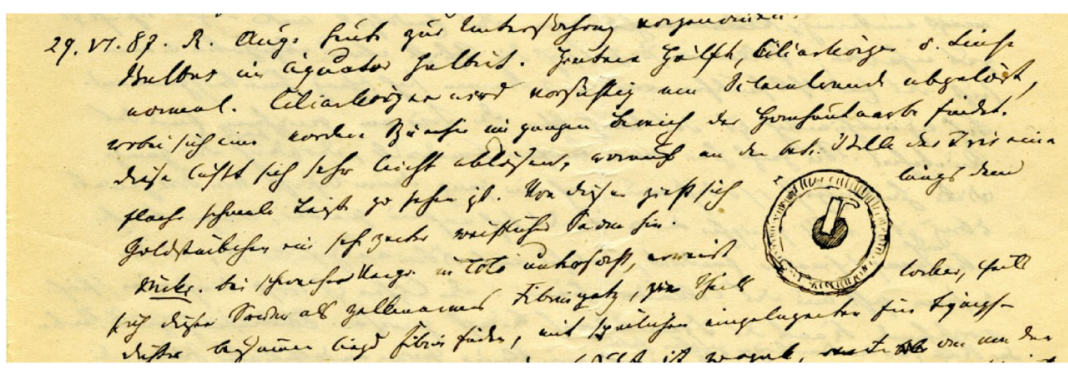

Abb. 6 Ausschnitt aus Heft 8, Versuch 54, aus dem Jahr 1887 über Goldstreifen in die vordere Augenkammer. Skizze zeigt halbierten Bulbus mit Blick auf Iris und Hornhaut, die miteinander verwachsen waren, mit einem weißlichen Saum um das Goldstück

lässt sich erkennen, dass Leber sein Aufschreiben unterbrach und eine Skizze anfertigte, die er dann im folgenden Text weiter beschrieb.

Die in der Protokollsammlung vorkommenden Skizzen stellen einzelne Beschreibungen aus dem Text bildlich dar. ${ }^{19}$ Die Skizzen sind also keine Visualisierungen des direkten mikroskopischen Bildes, sondern vielmehr der verschriftlichten Beobachtung. Ein Bezug zu Lebers Entzündungstheorie haben sie aber nicht, sondern sie wirken fast wie zufällig entstanden. Gerade an den Skizzen wird deutlich, welchen Stellenwert das Aufschreiben und die Notizen selbst für Leber hatten, da aus den Beschreibungen die Bilder entstanden. Über diese Skizzen wurde also ein besserer Zugang zum Geschriebenen als zur experimentellen Beobachtung gewonnen.

An einigen Stellen finden sich zu hauptsächlich in Lebers Handschrift geschriebenen Einträgen auch Abschnitte, die in anderen Handschriften verfasst sind. Die Abbildung 7 zeigt beispielhaft, wie sich die Einträge nahtlos in ein Versuchsprotokoll oder eine Versuchsserie einfügen.

Der weitere Protokollant wurde also in den jeweiligen Versuch bzw. dessen Verschriftlichung einbezogen. Die fremden Handschriften finden sich vor allem bei der Beurteilung der mikroskopischen Untersuchung. Die weiteren Protokollanten waren also eng vertraut mit Lebers Forschung und wiesen eine gewisse Expertise in Bezug auf die Untersuchungstechniken und das -objekt auf. Es handelte sich dabei wahrscheinlich um wissenschaftliche Assistenten Lebers, die er an seiner Entzündungsforschung teilhaben ließ, da sich Verbindungen zwischen einzelnen gemeinschaftlich durchgeführten Experimenten und Publikationen von Lebers Assistenten nachweisen lassen (Tückermann 1892: 60-92). In diesen Fällen gewährleistete die Protokollierung, dass Leber und seine Assistenten über den Versuchsstand den Überblick behielten. In Lebers Experimentalsystem hält das Aufschreiben die flüchtigen Entzündungsprozesse fest, visualisiert im Schreiben Fixiertes, dient als Kommunikationsmittel zwischen den Labormitarbeitern und bietet Möglichkeiten zur weiteren Bearbeitung an. 


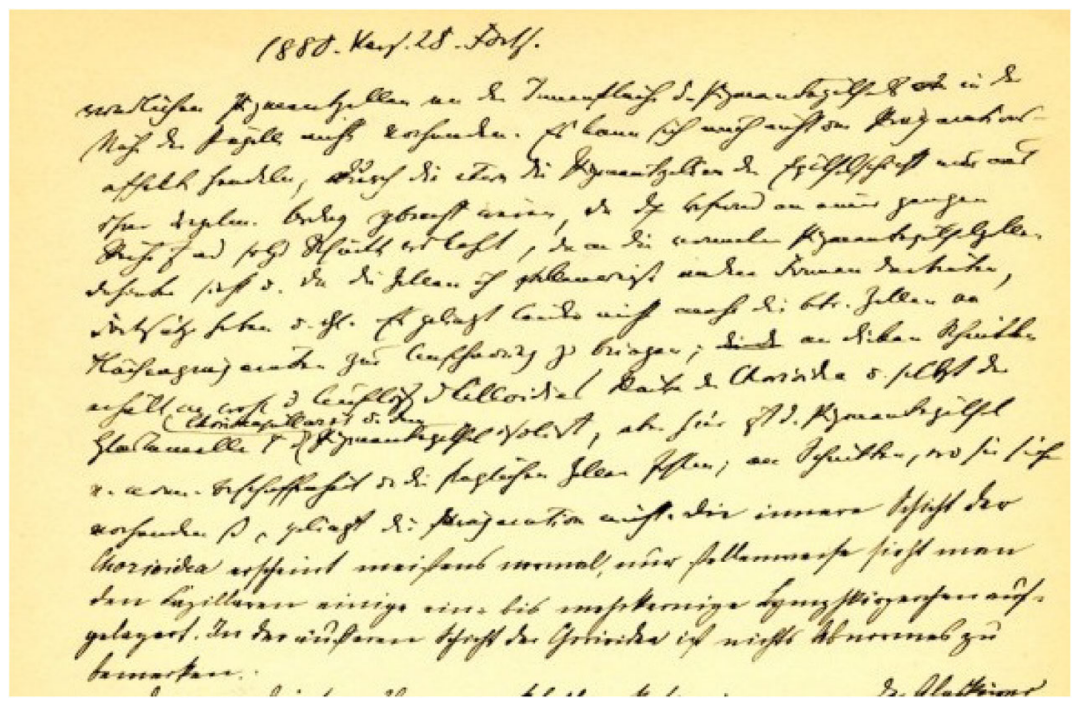

Abb. 7 Ausschnitt über die mikroskopische Beurteilung aus Heft 8, Versuch 25 vom 29.7.1889 über Golddraht im Glaskörper

\section{Sammeln}

Über das Sammeln als wissenschaftliche Arbeitstechnik zum Generieren von neuem Wissen sind verschiedene Beiträge erschienen (vgl. beispielhaft te Heesen \& Spary 2001). Auch in Lebers Forschungspraxis lässt sich die Anwendung dieser Arbeitstechnik feststellen. So sammelte Leber in den Protokollen seine Versuchsbeobachtungen. Er führte immer wieder den gleichen Versuchsaufbau durch und erreichte damit eine hohe Zahl an reproduzierbaren Entzündungserscheinungen. Neben den Protokollen bewahrte Leber auch die histologischen Präparate auf. Mit beiden Quellen konnte er Versuche, die 1879 begonnen hatten, mit neuen Versuchsreihen von 1883 oder 1886 in Bezug setzen und an älteren Versuchsreihen weiterarbeiten. $^{20}$

Auf diese Weise konnte Leber seine Beobachtungen mit der Entzündungsforschung abgleichen, wenn neue Theorien in der Wissenschaft diskutiert wurden. Ebenso gelang es ihm, neu erworbene Erkenntnisse an seinen aufbewahrten Präparaten zu überprüfen und zu seinen schriftlichen Notizen vergleichend in Beziehung zu setzen. Damit wurde Lebers Forschung zugleich vorangetrieben, denn erst aus der Häufung ähnlicher Entzündungserscheinungen zeigte sich, dass der Einsatz des inerten Fremdmaterials produktiv war. Mit dem Sammeln der Protokolle und Präparate konnte Leber seine Versuchsreihen also zugleich fortführen und offen halten. So war es ihm möglich, die Protokolle beispielsweise 1889 bzw. 1890 um zahlreiche histologische Untersuchungen zu ergänzen und selbst noch im 20. Jahrhundert fortzuführen und um Einträge zu erweitern. 
Grundlage dafür war, dass Leber seine Protokolle auf losem Papier führte, sodass diese beliebig arrangiert werden konnten und sich, auch wenn längst schon viele weitere Versuchsserien begonnen waren, leicht ergänzen ließen. Die Produktivität der Fremdkörperversuche und der Gewinn weiterer Erkenntnisse wurden dadurch weiter herausgefordert, dass Leber die einzelnen Protokolle sowie die zusammengestellten Versuchsserien für eine weitere Bearbeitung offen ließ. So finden sich unter der Protokollsammlung auch noch Versuchsreihen von 1892 und 1897, also nach der Veröffentlichung seiner Monographie 1891 und damit nach der versuchten Einführung seiner Entzündungstheorie in die Wissenschaft. ${ }^{21}$ Aus diesen Versuchsreihen konnte Leber neues Wissen zum Krankheitsbild der Konjunktivitis petrificans (eine Form der Bindehautentzündung des Auges) gewinnen und die Vorgänge bei Perforationen am Hornhautrand nachvollziehen. ${ }^{22}$ Die epistemische Dynamik von Lebers Protokollsammlung reichte also über die Ziele der Versuchsreihen hinaus. Der von Leber geschaffene Arbeitsapparat erwies sich als produktives Instrument, durch das einerseits quasi überschüssige Versuchsbeobachtungen entstanden, die Leber für weitere Forschungsprojekte heranzog. Andererseits veranlasste er Leber auch dazu, die Protokollsammlung weiter zu führen.

\section{Vergleichen}

Leber beschrieb bei einem Fremdkörperversuch im Glaskörper 1889: „Bei nochmaliger Durchsicht der Präparate $u$. Vergleichung + Schnitten v. d. normalen Papille stellt sich doch eine Anzahl von Veränderungen als sicher pathologisch heraus. “23 Er verglich alte Protokolleinträge und aufbewahrte Präparate mit Präparaten gesunder Augen, was seine vorherigen Beobachtungen bestätigte. ${ }^{24}$ Die Versuchsreihen standen also nicht für sich allein, sondern griffen ineinander. Es kam sogar vor, dass durch die angestellten Vergleiche andere Versuche erneut untersucht wurden. ${ }^{25}$ Hier zeigt sich deutlich das wechselseitige Verhältnis von experimenteller und schriftlicher Arbeit. Denn erst das Aufschreiben der Beobachtungen macht einen Vergleich der entzündlichen Reaktionen auch über einen längeren Zeitraum möglich. Das Schriftliche bricht an dieser Stelle also die zeitliche und örtliche Dimension der experimentellen Arbeit auf (Latour 1990: 44-47). Damit kann die Protokollsammlung zeitliche und örtliche Diskontinuitäten innerhalb der experimentellen Arbeit überbrücken.

Durch Nachlesen und Vergleichen konnte Leber zudem Unterschiede in scheinbar gleichen Versuchsanordnungen erkennen. So konnte er mögliche Fehlerquellen wie eine Verunreinigung des Fremdkörpers identifizieren, wodurch weitere Versuche entstanden, um die Wirkung chemisch eindeutig nachzuweisen. Das Vergleichen ist damit zugleich ein schriftlicher Verfahrensschritt, der die gewonnenen Erkenntnisse stabilisiert. Das Medium, das die Protokollsammlung darstellt, birgt in sich sowohl Instrument als auch 
Verfahren. So ermöglicht sie, dass Differenzen und Gemeinsamkeiten offenbart werden, und gleichzeitig fungiert sie als Arbeitsfläche, um damit umzugehen.

\section{Überarbeiten}

Innerhalb der Protokolleinträge finden sich zahlreiche Überarbeitungsformen (vgl. Abb. 8). Diese Überarbeitungen müssen zu verschiedenen Zeitpunkten vorgenommen worden sein. Die in der Abbildung 8 deutlich werdenden

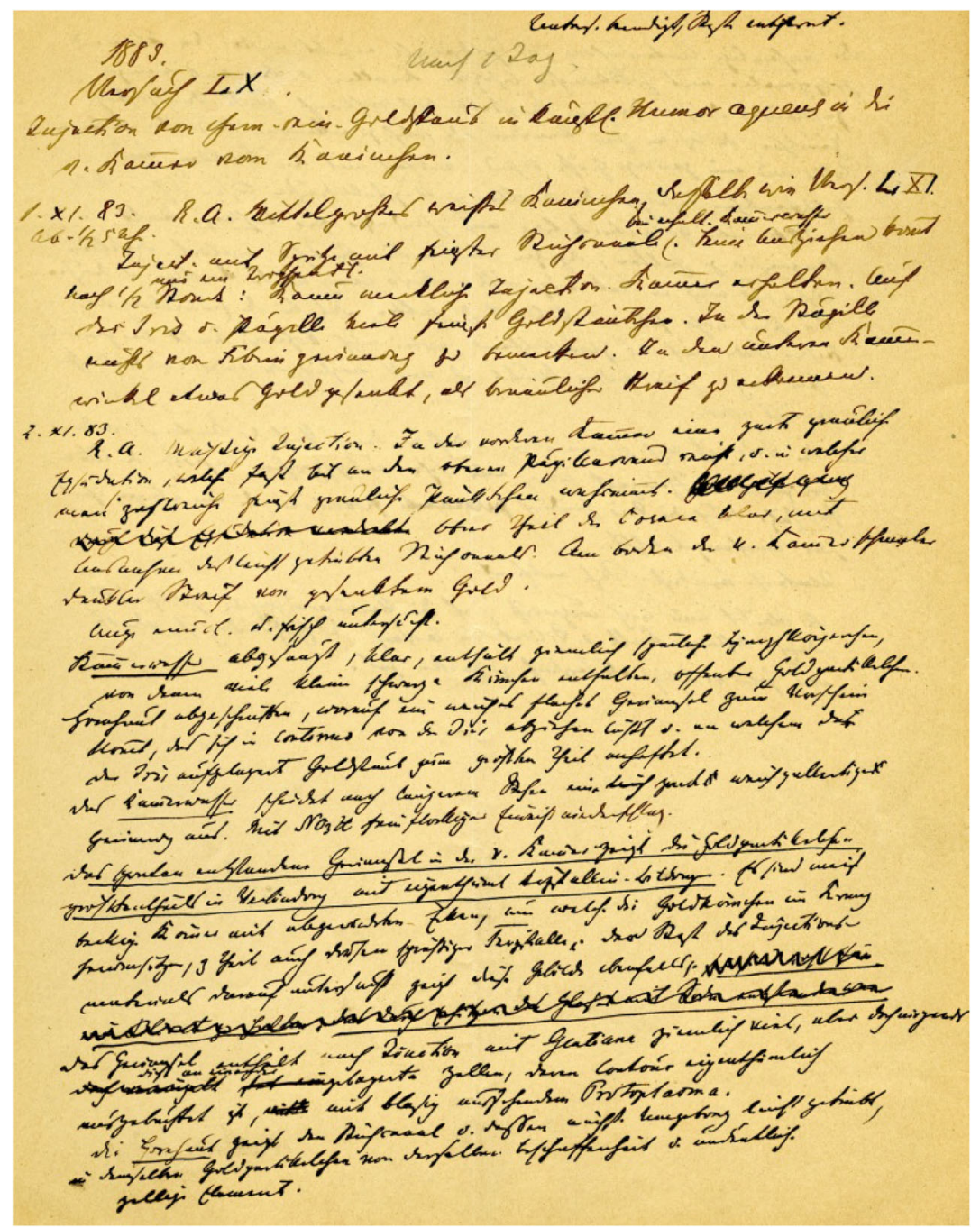

Abb. 8 Aus Heft 5, Versuch LX aus dem Jahr 1883 über die Injektion von Goldstaub in die vordere Augenkammer. Nachträglich wurden das Versuchsende, die Beseitigung der Reste und die Zeit bis zur Enukleation des Auges notiert 


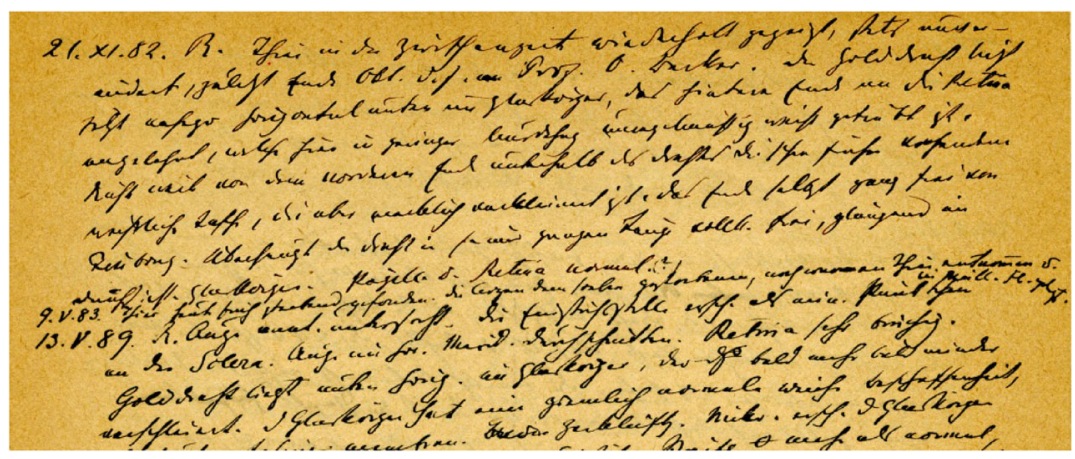

Abb. 9 Ausschnitt des Protokolls aus Heft 8, Versuch 25 aus dem Jahr 1880 über Golddraht im Glaskörper. Hier zeigt sich ein nachträglicher Eintrag über den Tod des Versuchstieres

Textveränderungen stellen nämlich unterschiedliche Schritte des Bearbeitungsprozesses dar. So sind die Ergänzungen und Streichungen in den oberen Einträgen wahrscheinlich während des Protokollierens entstanden. Die Unterstreichungen und Korrekturen im unteren Abschnitt hingegen sind eher nach Versuchsende vorgenommen worden, denn sie haben für den Leser bereits einen funktionalen Charakter. Damit ist gemeint, dass sie den Text ordnen, ihn übersichtlich strukturieren und auf die wichtigsten Punkte hinweisen.

Vermutlich wurden die Unterstreichungen sogar erst zwischen 1889 und $1891 \mathrm{im}$ Zusammenhang mit dem Abfassen der Monographie vorgenommen, da sie sich vor allem bei den zu dem Zeitpunkt angestellten histologischen Untersuchungen finden lassen. Andere Überarbeitungsformen sind nachträgliche Ergänzungen, wie in Abbildung 9 der zusätzliche Eintrag zwischen dem „21.XI.82“ und dem „13.V.89“, dass am „9.V.83“ das Versuchstier gestorben sei. Dieser Eintrag wurde daher mindestens sechs Jahre nach Tod des Kaninchens eingefügt.

Leber bearbeitete seine Aufzeichnungen also zu verschiedenen Zeitpunkten, sowohl unmittelbar während des Protokolleintrags als auch Jahre später bei einer erneuten Durchsicht. In Abbildung 10 erkennt man einen ganzen durchgestrichenen Absatz.

Hier wurden nicht gelungene Schnitte eines Augenpräparates beschrieben, auf denen sich wenige pathologische Veränderungen fanden. Der darauf folgende Abschnitt geht auf gelungene Schnitte ein, auf denen Endothelwucherung und Leukozyteneinwanderung zu sehen waren. Das Durchstreichen entfernte also Beschreibungen, die negative Resultate beinhalten, Beobachtungen, die keinen Erkenntnisgewinn oder Beleg für Lebers Entzündungstheorie darstellten. Da Leber zu verschiedenen Zeitpunkten seine Beobachtungen durchstrich, überschrieb oder ergänzte, entwickelten sich auch die Protokolle mit seinem Erkenntnisfortschritt weiter. Das Überarbeiten 


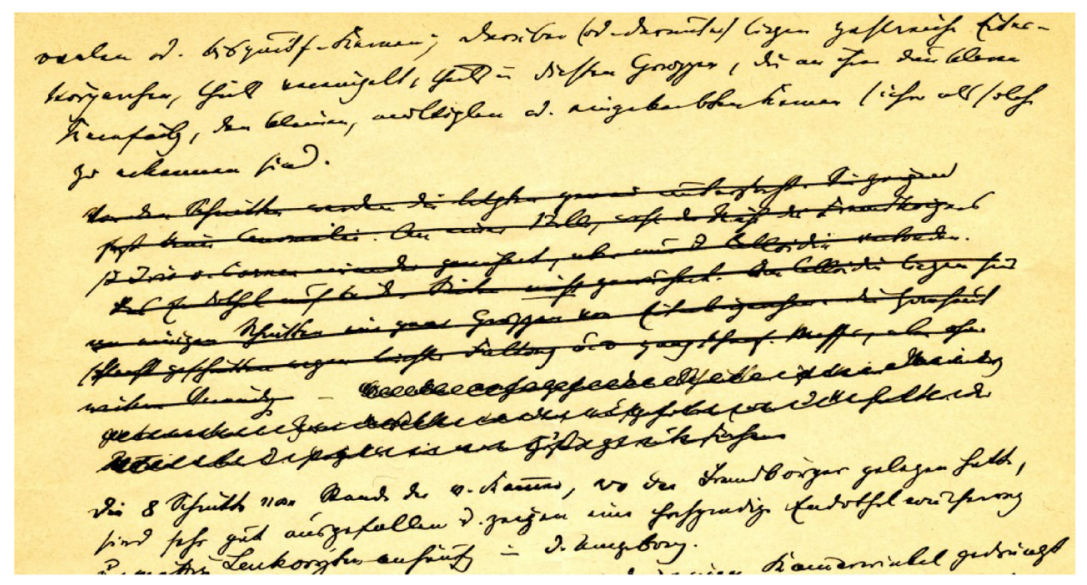

Abb. 10 Ausschnitt des Protokolls aus Heft 8, Versuch 51 vom 8.8.1889 über die Einführung von Goldblech in die vordere Augenkammer

der notierten Versuchsbeobachtungen spitzte diese auf seine Entzündungstheorie hin $\mathrm{zu}$.

\section{Gruppieren}

Es decken sich innerhalb der Monographie einzelne Kapitel bzw. Abschnitte mit Lebers Versuchsprotokollen aus verschiedenen Heften. Es ist aber auch eine Kongruenz von einem ganzen Heft mit einem Abschnitt der Monographie festzustellen. Es lässt sich daher als weiterer Verfahrensschritt ein Zusammenstellen der Versuchsprotokolle postulieren. Die verschiedenen Versuchsnummerierungen erklären sich dann damit, dass es sich um eine Auswahl von Protokollen aus einer viel umfangreicheren Sammlung von Versuchsreihen handelt. Die Sortierung nach Injektionsmaterial und -ort war nur möglich, da die Protokolle auf losen Blättern verfasst wurden. Erst dieses Arrangieren der Protokolle-im Gegensatz $\mathrm{zu}$ Eintragungen in einem gebundenen Laborbuch-ermöglichte es, die einzelnen Protokolle in neue Zusammenhänge zu stellen und sie damit aus dem Sachzusammenhang der fortlaufenden einfachen Dokumentation $\mathrm{zu}$ entheben. Deutlich wird das Ausnutzen der Beweglichkeit der losen Zettel an der Abschrift des Teilversuches XXXVI b von 1879. In Heft 8 finden sich nämlich zwei Protokolle desselben Versuchs: sowohl das gesamte Protokoll von Versuch XXXVI a und $\mathrm{b}$ als auch eine Abschrift des Teilversuches XXXVI b. ${ }^{26}$ Hier zeigt sich die Bedeutung der thematischen Sortierung. Da es in dem Teilversuch b um die Injektion von Silber ging, wurde es nochmal abgeschrieben und in den Themenbereich Silberinjektion eingeordnet. Das gesamte Protokoll XXXVI a und b wurde in den Themenbereich Goldinjektion einsortiert. Neben dem Sortieren der losen Protokollblätter zu neuen Sachzusammenhängen in Form der vorgefundenen Hefte wendete Leber auch eine andere Form der Gruppierung 


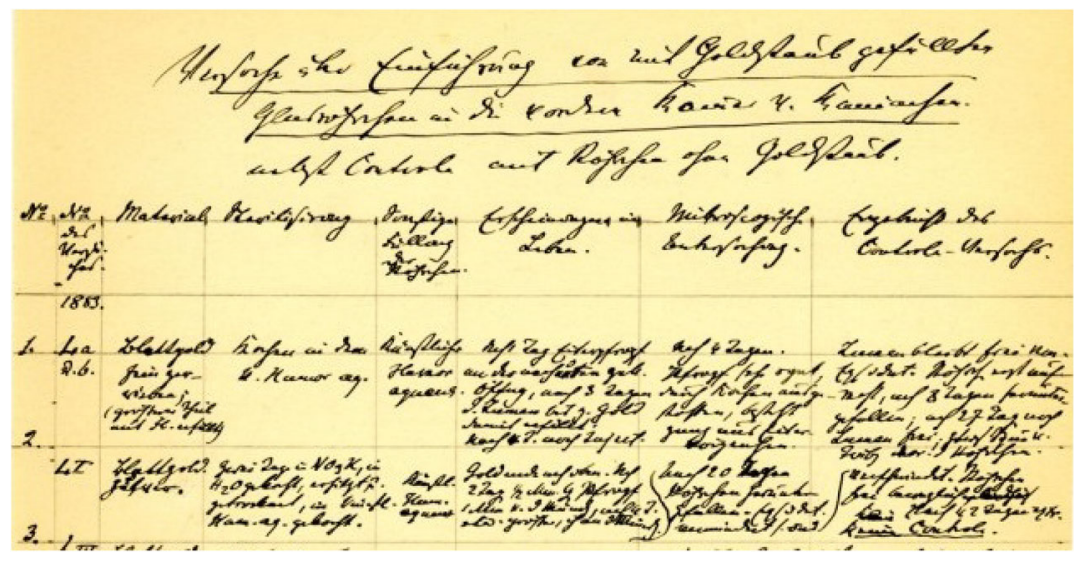

Abb. 11 Ausschnitt aus einer Tabelle in Heft 9 über Versuche mit Röhrchen mit Goldstaub und ohne Inhalt in der vorderen Augenkammer

an, indem er zur weiteren Übersicht zusätzliche Tabellen anfertigte. In den Heften 9 und 10 finden sich zu Beginn tabellarische Auflistungen der im Heft nachfolgenden Versuche (vgl. Abb. 11 und 12).

Die unterschiedliche Gestaltung der beiden Tabellen deutet darauf hin, dass sie nach unterschiedlichen Gesichtspunkten erstellt wurden. Die Abbildung 11 zeigt den Ausschnitt einer Tabelle aus Heft 9, die sehr sauber und ordentlich angefertigt worden ist. Die Tabelle verschafft einen schnellen Überblick über den Versuchsaufbau und -verlauf. Unterschiede lassen sich hier in der Art der Sterilisierung erkennen. Gleiche Versuchsbeobachtungen kann man ebenfalls schnell erfassen. Im Gegensatz dazu wirkt die Auflistung der Versuche aus Heft 10 wie schnell zu Papier gebracht und als ob die Übertragung in Reinschrift noch fehlen würde. Diese Übersicht versammelt vor allem die Ergebnisse der anatomischen Untersuchung und notiert dazu die Dauer der Fremdkörpereinwirkung bis zum Tode des Kaninchens. Beide Tabellen tragen damit zur schnellen Erfassung der Versuchsinhalte bei, jedoch wurde ein unterschiedlicher Schwerpunkt auf die enthaltenen Beschreibungen gelegt, sodass aus ihnen verschiedene Belege für Lebers Entzündungstheorie $\mathrm{zu}$ entnehmen waren. Das Selektieren, Sortieren und Zusammenfassen machte die in den Protokollen enthaltenen einzelnen Beobachtungen also leichter zugänglich, ordnete sie und rückte sie in neue Kontexte.

Die Verfahrensschritte dokumentieren, wie Leber sein Wissen zum Entzündungsgeschehen über seine Schreibarbeit entwickelte und im Bearbeiten zu seiner Entzündungstheorie verdichtete. Die Verschriftlichung der Beobachtungen stellte den ersten Schritt dar, um die flüchtigen biologischen Prozesse anzuhalten und mit ihnen umgehen zu können. So konnten Vergleiche angestellt werden und es ließen sich reproduzierbare Effekte der Experimente erfassen. Entscheidend dafür war die Aufbewahrung der 


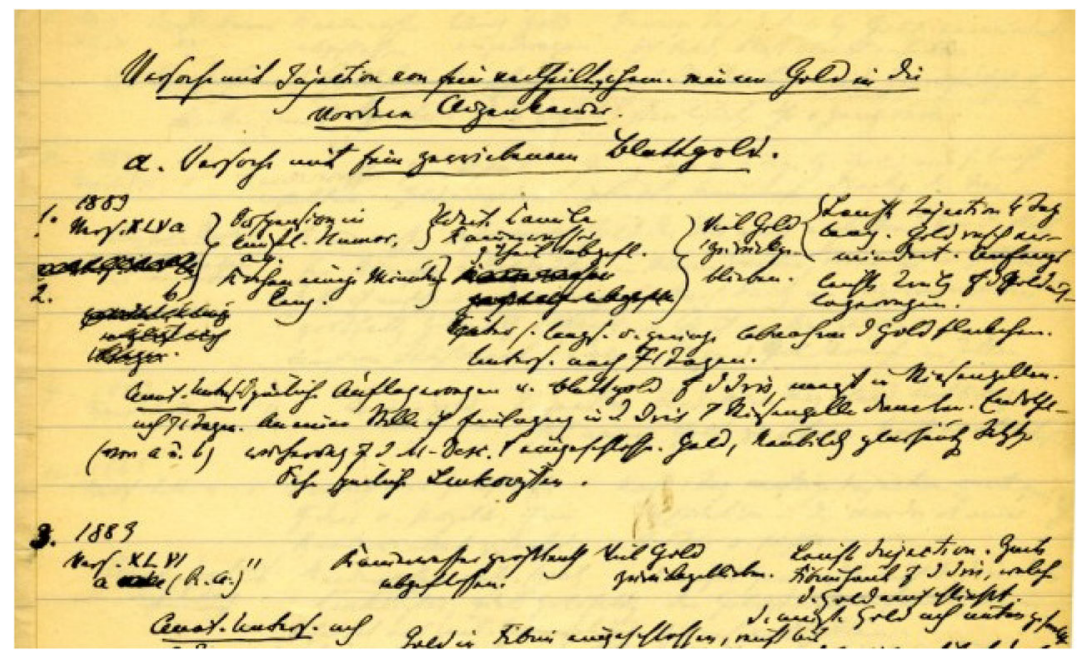

Abb. 12 Ausschnitt einer Auflistung in Heft 10 über Versuche mit Gold in der vorderen Augenkammer

einzelnen Versuchsprotokolle und der histologischen Präparate. Erst mit dem Sammeln entstand ein Fundus an notierten Beobachtungen, die eine Aussage über die Häufigkeit und Wiederholbarkeit gleicher Versuchsergebnisse erlaubten. Mit dem Überarbeiten der Protokolleinträge gelang es, die bloßen Beobachtungen aus den Experimenten zu Befunden und bestätigten Ergebnissen zu verfestigten. Auf losen Zetteln notiert waren Lebers Beobachtungen immutable mobiles, die selektiert, sortiert und ergänzt werden konnten. Lebers Experimentalsystem startete mit der überraschenden Beobachtung, dass auch durch inertes Material eine Entzündungsreaktion ausgelöst werden kann. Aber im Kontext des starren Denkstils der Bakteriologen geriet es rasch in einen unsicheren Zustand. Immer wieder wurden mit dem gleichen Versuchsaufbau verschiedene Fremdmaterialien getestet. Die parallel zu den Experimenten laufende Schreibarbeit entwickelte sich zu einer Stabilisierungsstrategie seiner Beobachtungen und setzte neue Dynamiken frei.

Als besondere Papiertechnik wird die Protokollsammlung im Laufe des Forschungsprozesses mehr und mehr zur Prüfinstanz der experimentellen Beobachtungen. Die Bearbeitungsformen der Notizen sollen hier jedoch nicht als manipulativer Akt dargestellt werden, der die Objektivität der experimentellen Erkenntnisse in Frage stellt. Denn die schriftlichen Überarbeitungen wurden mit Hilfe neuer Versuchsergebnisse bzw. aus der Nachuntersuchung alter Präparate getroffen und entstanden nicht allein aus den Notizen selbst. An Lebers Experimentalsystem verdeutlicht sich also die enge Verzahnung von experimenteller und schriftlicher Arbeit. Lebers Experimentalsystem verweist aber auch auf den Aufwand, den ein Forscher betreibt, der mit seinen Erkenntnissen zunächst keine Anerkennung in der 
wissenschaftlichen Öffentlichkeit bekam. Nicht nur die experimentelle Arbeit war bei Leber mit einem hohen zeitlichen Ausmaß verbunden, sondern auch seine beim Protokollieren entstandenen schriftlichen Techniken zur Stabilisierung und Verdichtung seiner Theorie zogen sich über viele Jahre.

\section{Transformation der Beobachtungen zu wissenschaftlichen Tatsachen}

Im Kontext des sich für immunologische Forschungen öffnenden Entzündungsdiskurses gewann Lebers Forschung erst nach der noch 1888 ohne Echo verhallten Veröffentlichung seiner Entzündungstheorie an Relevanz, wie sich wiederum an den Bearbeitungsschritten in der Protokollsammlung zeigen lässt. Seine Schreibarbeit in den Jahren 1889 und 1890 transformierte die experimentellen Beobachtungen nun $\mathrm{zu}$ neuen Befunden: Alte Einträge wurden erneut betrachtet, korrigiert oder ergänzt, hervorgehoben und tabellarisch auf das Wesentliche reduziert. Wie bereits erläutert, ging Leber in seinen Experimenten vergleichend vor. In besonderer Weise verdeutlicht die Korrektur einer zuvor protokollierten Beobachtung im Versuch LX von 1883 über die Injektion von Goldstaub in die vordere Augenkammer die Transformation zu Befunden. Zunächst hieß es: „Das Gerinnsel enthält nach Tinction mit Gentiana ziemlich viel, aber doch vereinzelt stark eingelagert. Zellen, deren Contour eigenthümlich ausgebuchtet ist" Nach der Überarbeitung lautete es: „Das Gerinnsel enthält nach Tinction mit Gentiana ziemlich viel, aber doch nirgends dicht aneinander gelagert. Zellen, deren Contour eigenthümlich ausgebuchtet ist. “27

Damit wurden die Beobachtungen auf ihre Eignung für die Entzündungstheorie einer physiologischen Abwehr geprüft und bekamen so die Funktion von Beweisstücken. Wurden sie in der Monographie im gleichen Format wie in der Protokollsammlung aufgenommen, so dienten sie auch dem Zweck, den dortigen Ausführungen eine gewisse Objektivität zu verleihen. Diese sollte dadurch bestärkt werden, dass Leber seine im Experiment unmittelbar aufgetretenen Versuchsbeobachtungen als Referenz anführte und nicht frei interpretierte. Aber diese scheinbare Unmittelbarkeit war erst das Ergebnis sorgfältiger Verschriftlichung, Überarbeitung, Bestätigung, Zergliederung, Sortierung und Gruppierung. Das zeigt sich insbesondere dort, wo in Teilen die Reihenfolge der Versuche aus einem Protokollheft beibehalten wurde, also die komplexe Zusammenstellung der Protokollsammlung zur Konstruktion der Kapitel diente. ${ }^{28}$ Die Monographie stellte das Protokoll in einen Argumentationszusammenhang und gab weitere Hinweise, die auf die Motivation zu den Versuchen schließen lassen-über die die Protokolle selbst keine Auskunft geben (Leber 1891: 209). Dort konnten außerdem Deutungen 
vorgenommen werden: Vermutungen über die Auflösung eines eingebrachten Glassplitters wurden beispielsweise negiert. ${ }^{29}$

Des Weiteren kürzte Leber die Protokolleinträge und schrieb sie so um, dass sie nur die zum Verständnis der Entzündungstheorie notwendigen Informationen im Sinne seiner Argumentation enthielten. So finden sich im Protokoll von Versuch XXV a und b aus dem Jahr 1879 über die Injektion von einem Glassplitter in den Glaskörper täglich Einträge. Im Gegensatz dazu wurde in der Monographie nur jeder vierte Eintrag übernommen (ebd.: 216). Im Protokoll von Versuch 26 aus dem Jahr 1880 über die Einführung von Golddraht in den Glaskörper notierte Leber beispielsweise eine „Linsentrübung", die er in der Monographie als "traumatische Katarakt" bezeichnete (ebd.: 203). Oder er beschrieb in Heft 7 unter dem Vermerk „Forts. v. Vers. XXXV R.A. am 24.1.1882“ den Tod eines Versuchskaninchens als „zufällig“, obwohl es an „Bisswunden“ gestorben war (ebd.: 218). Viele der experimentellen Beobachtungen, die Leber in seiner Protokollsammlung dokumentierte, dienen in der Monographie als Belege.

Inmitten der um Virchows Zellularpathologie, Kochs Mikrobiologie und Metschnikoffs Phagozytentheorie geführten Entzündungsdebatte publizierte Leber also 1891 seine Versuchsprotokolle als Indizien für seine Entzündungstheorie. Mit seinen Experimenten zur chemischen Attraktion der Leukozyten konnte er Anfang der 1890er Jahre an die in der Wissenschaft seit Kurzem vermehrt diskutierten Theorien zu körpereigenen Abwehrreaktionen in Folge bakterieller Infektionen anknüpfen. Die Bakteriologen Carl Flügge (1847-1923) und Eugen Czaplewski (1865-1945) beschrieben ausführlich verschiedene Hypothesen zur Immunität (Flügge 1888: 208-230; Czaplewski 1892: 348-474). Unter anderem nahmen sie kritisch Stellung zur Phagozytentheorie, in deren Zusammenhang auch auf Beobachtungen von einer Chemotaxis der Leukozyten verwiesen wurde, die von den Bakteriologen Hans Buchner (1850-1902) und Jules Bordet (1870-1961) 1890 und 1891gemacht worden waren.

Lebers Monographie reihte sich international gesehen in mehrere nahezu zeitgleich veröffentlichte Theorien zur Chemotaxis ein (Hertwig 1923: 192). Die in ihr formulierten Überlegungen wurden am Ende des 19. Jahrhunderts jedoch deshalb kaum rezipiert, da Leber als Ophthalmologe nicht zum inneren Kreis der bakteriologisch orientierten Forscher gehörte. Zudem konzentrierte sich die Forschergemeinschaft weiterhin auf mikrobiologische Aspekte und thematisierte Entzündungserscheinungen nur am Rande, wobei die Chemotaxis als Teilvorgang der Entzündung anerkannt schien und nicht in Frage gestellt wurde (Kaposi 1892: 10-53; Grabitschewsky 1900: 104-122). Denn die Vorstellung der chemischen Attraktion von beweglichen Zellen stand keineswegs im Widerspruch zu den Beobachtungen anwesender Leukozyten im Gebiet der eingedrungenen Mikroorganismen. So urteilte beispielsweise Czaplewski: „Durch die Untersuchungen von Buchner [...] 
einerseits, Massart und Bordet, Bouchard u. A. andererseits wissen wir, dass diese chemotactische Reizbarkeit der Leukozyten durch Bacterien [...] gesteigert wird." (Czaplewski 1892: 425).

Erst zu Beginn des 20. Jahrhunderts mehrte sich Literatur, die nun auch dem Entzündungsmechanismus Lebers Aufmerksamkeit schenkte und seine Experimente in Bezug auf das Leukozytenverhalten als Forschungsbeitrag bewertete (Kisskalt 1903: 1-60; Kästner 1924: 479-516). Der Bakteriologe Karl Kisskalt (1875-1962) konstatierte etwa: „Bei der grossen Wichtigkeit [...] seien hier auch die Arbeiten erwähnt, die sich mit den Eigenschaften derselben [Leukozyten] beschäftigen, soweit sie für den Infectionsprocess von Bedeutung sind. Vor Allem kommen hier die Arbeiten von Leber in Betracht." (Kisskalt 1903: 11). Das erst seit 1900 wieder steigende Interesse an der Grundlagenforschung zur Entzündung verdeutlicht auch die Veröffentlichung des Pathologen Felix Marchand (1846-1928) über eine Stellungnahme zum Entzündungsbegriff, da dieser von verschiedenen Wissenschaftlern angezweifelt wurde. Marchand reflektierte den Zusammenhang zwischen der Entzündung als Erkrankung, wie lange von der Bakteriologie vertreten, und der Vorstellung einer physiologischen Abwehrreaktion, was unter den Wissenschaftlern zu Uneinigkeit und Ablehnung des Entzündungsbegriffs geführt hatte. Hierbei positionierte er sich klar auf Seiten Lebers und dessen Entzündungstheorie (Marchand 1921: 245-299).

Lebers Forschungsansatz zur Untersuchung der Entzündung erwies sich 1879 noch als progressiv. Als er die Theorie der Chemotaxis der Leukozyten in den 1890er Jahren in seiner Monographie in Belegform aufführte, wurde sie im Fachdiskurs bereits als Tatsache behandelt. Das zeigt sich an den wenigen kritischen Auseinandersetzungen mit der Theorie der Chemotaxis wie auch der fehlenden wissenschaftlichen Anerkennung zu Beginn des 20. Jahrhunderts. Der parallele Fortschritt bakteriologischer Erkenntnisse, Erfahrungen von Schutzimpfungen und die Diskussion um die Funktion von Entzündungen markieren die Erweiterung des bakteriologischen Denkstils, wodurch Vorstellungen von der körpereigenen Abwehr in der Wissenschaft populärer wurden. Leber hatte mit dem Verharren in seinem Experimentalsystem den Anschluss an den Wissenschaftsdiskurs verloren. Aus der Verunsicherung heraus und aufgrund des peniblen Anspruchs an sich selbst als Forscher entstand eine über drei Jahrzehnte fortgeführte Forschung zur Entzündung. Dass seine Monographie erst spät rezipiert wurde, lässt sich eben auch darauf zurückführen, dass er nicht zum inneren Kreis der Entzündungsforscher jener Tage gehörte.

Nach Lebers Tod 1917 wurde seine ausdauernde und akribische Forschung an der Entzündung noch vom Kreis der deutschsprachigen Ophthalmologen gewürdigt (Wagenmann 1917: II-VIII). In der heutigen deutschsprachigen Fachliteratur wird hingegen kaum noch auf Lebers Entzündungsforschung verwiesen. Demgegenüber rekurriert die 
englischsprachige Fachliteratur bis in die Gegenwart ausgiebig auf Lebers Einführung der Chemotaxis der Leukozyten (Wells 1920; McCutcheon 1946: 319-336; Vicker 1986: 263-280; Tian 2008: 1-8). Dieses dürfte mitunter darin begründet liegen, dass sich Leber in England mit einigen Vorträgen zur Entzündung einen Namen machen konnte (Leber 1891: 1328f., 1446-1448; Orbituary 1917: 648-652).

Diese unterschiedlichen Rezeptionsmuster von Lebers Werk sind vor dem Hintergrund zu verstehen, dass die Immunologie im deutschsprachigen Raum Anfang des 20. Jahrhunderts eine von der internationalen abweichende Entwicklung nahm. Die Forschung zur Immunität war in Deutschland stark auf die Möglichkeiten der Heilung einer bakteriellen Infektion ausgerichtet. Lebers Forschungsergebnisse zur Rolle der Leukozyten und der Entzündung im Infektionsgeschehen stieß hier auf wenig Interesse, da diese für die Forschungsausrichtung der Bakteriologen scheinbar keine Relevanz besaßen (Silverstein 2008: 455-464). Auf internationalem Parkett entwickelte sich die Immunologie hingegen weiter und differenzierte sich dabei zu einer eigenen Disziplin aus, was mitunter in der Gründung der American Association of Immunologists im Jahr 1913 ihren Ausdruck fand (ebd.: 457). Somit ist die divergente Rezeption von Lebers Entzündungsforschung zugleich auch Spiegelbild der Genese der Immunologie als Spezialdisziplin. Lebers Forschung illustriert die Phase einer Denkstiländerung. Zu Beginn seiner Forschung war die „Beharrungstendenz“ (Fleck 1980: 40) der Wissenschaftler groß und die Bakteriologie hatte die alleinige Deutungshoheit in Bezug auf die Entzündung. Die Einseitigkeit und das Festhalten an bisherigen Erkenntnissen provozierte bei Leber ein von der wissenschaftlichen Öffentlichkeit abgekehrtes Forschen. Jedoch zeigten sich auch in Lebers eigenen Forschungen Beharrungskräfte. Er hielt an seinem Experimentalsystem fest. Seine Forschungen wurden von der Denkstiländerung eingeholt, sodass sich seine frühen Erkenntnisse zur körpereigenen Abwehr und chemischen Anlockung der Leukozyten in bereits publiziertes Wissen einfügten. In der Wissenschaft wurden seine Erkenntnisse damit bereits als Tatsachen wahrgenommen.

\section{Lebers Protokollsammlung als Papiertechnik im historischen Kontext}

Ende des 19. Jahrhunderts wurde die Chemotaxis von Leukozyten in die Entzündungsforschung eingeführt. Die vorliegende Studie rekonstruierte diese Entwicklung auf Grundlage der Laborprotokolle des Ophthalmologen Theodor Lebers und setzte dabei die mikrohistorische Analyse in Bezug zu einer makrohistorischen Perspektivierung. Die besondere Funktion der Protokollsammlung in Lebers Experimentalsystem-hier als Beispiel einer 
spezifischen Papiertechnik vorgestellt-lässt sich einerseits nur im Vergleich mit der von Leber verfassten Monographie begreifen. Andererseits ließ sich die Bedeutung der in der Mikroanalyse gefundenen schriftlichen Bearbeitungen erst mit der Kontextualisierung der historischen Entzündungsforschung und hier im Speziellen mit der von Ludwig Fleck aus seiner eigenen historischen Perspektive beurteilten Entzündungsforschung herausarbeiten.

Die historische Untersuchung der Entzündungsforschung im späten 19. Jahrhundert, während des Übergangs von einer durch die Bakteriologie bestimmten Sicht zu einer immunologischen Auffassung der Entzündung als natürlichem Abwehrprozess, wird durch die Mikroanalyse der Protokollsammlung Lebers also fruchtbar ergänzt. Auf diese Weise konnte gezeigt werden, inwiefern Leber sich in und mit seiner Forschung isolierte und worin sich die verzögerte Einführung der Chemotaxis in den Diskurs der Entzündungsforschung begründete. Lebers Forschungsapparat, der hier in Form einer Protokollsammlung und der entsprechenden Verschriftlichungsverfahren analysiert wurde, erweist sich dabei als ein vergleichsweise träges Element, das fortlaufend zur Stabilisierung der Versuchsergebnisse beitrug. Dieses Trägheitsmoment und die daraus resultierenden Verspätungen blieben der historischen Forschung vermutlich deshalb verborgen, weil sich ihr Fokus in erster Linie auf die neuen Entdeckungen und Errungenschaften der Wissenschaften richtete, die das Interesse der Zeitgenossen weckten.

\section{Anmerkungen}

1 Der Leiter berichtete, dass er die Sammlung als Assistenzarzt auf dem Dachboden der Göttinger Augenklinik gefunden und aufgehoben habe. Die Protokollsammlung wurde von der Autorin transkribiert. Original und Transkription sollen nach Abschluss des Projektes über das Online-Portal „Virtual Laboratory“ (vlp.mpiwg-berlin.mpg.de) digitalisiert und zugänglich gemacht werden. Die Protokollsammlung befindet sich aktuell im Archiv des Berliner Medizinhistorischen Museums der Charité.

2 In mehreren Veröffentlichungen hat insbesondere der langjährige Direktor der Heidelberger Augenklinik, Wolfgang Jäger, Leben und Werk Theodor Lebers dargestellt, vgl. Jäger 1985, 1988.

3 Diesen Aspekt vertieft Arthur Silverstein in seiner Monographie über die Geschichte der Immunologie (Silverstein 2009: 350).

4 Vgl. beispielsweise Heft 5 Versuch LXV-LXXII (1883), Einleitung: „Injection von chem. rein Goldstaub in die v. Kammer vom Kaninchen. Da bei der vorigen Versuchsreihe der Goldstaub bei nachträgl. mikr. Untersuchung nicht vollst. chem. rein gefunden wurde, (vgl. Vers. LX) wird eine neue Versuchsreihe aufgestellt". Leber hatte eine Verunreinigung mit Silikat und kohlensaurem Kalk des in die vordere Augenkammer injizierten Goldstaubs nachweisen können.

5 Heft 10 Versuch LXVIII a am 3.10.1883 „Die Injection hat also wieder Auswanderung zur Folge gehabt $u$. eher intensiver als bei dem vorigen Material, was bei der noch feineren Vertheilung begreiflich, warum eine chemisch Wirkung möglich ist."

6 Kennzeichen einer Entzündung war das Auftreten von Zellen. Der Pathologe Julius Cohnheim (1839-1884) hatte in den 1860er Jahren die Theorie aufgestellt, dass es sich bei diesen sogenannten Eiterkörperchen um die weißen Blutkörperchen (Leukozyten) handelte, die aktiv aus den Blutgefäßen ins Gewebe wanderten (Cohnheim 1914). 
7 Vgl. Heft 10 Versuch LXVIII b (1883) über die Injektion von Goldstaub in die vordere Augenkammer am 12.10.1883: „das Gold zum Theil frei, zum Theil als feine u. auch etwas gröbere Klümpchen in Zellen eingeschlossen“.

8 Heft 9 Vers. L a (1883) Einleitung: „Da chem. reines Goldpulver noch Auswanderung verursacht hatte, so soll untersucht werden, ob die Wirkung dieselbe bleibt, wenn der Goldstaub in einem Glasröhrchen eingeschlossen ist, von dem aus das eine Ende offen ist."

9 Vgl. Leber 1891: 61. Leber bezieht sich auf seinen 1888 veröffentlichten Zeitschriftenartikel: „Dass ich nicht früher als vor zwei Jahren damit hervorgetreten bin, hat seinen Grund darin, dass ich meine durch die Aspergillus-Versuche gewonnenen Anschauungen erst nach allen in Betracht kommenden Richtungen hin durch weitere Beobachtungen sicher stellen wollte."

10 Vgl. Heft 10 Vers. XLV a. u. b. (1883). Einleitung: „Zweck des Versuches ist zu sehen, ob auch bei Einführung zahlreicher kleiner Partikelchen chem. undiff. Substanz Fibringerinnung u. Einkapselungsvorgänge (Riesenzellenbildung) vollständig ausbleibt.“

11 Vgl. Briefe Theodor Lebers in der Graefe-Sammlung des Archiv des Medizinhistorischen Museums der Berliner Charité.

12 Leber führte weitere Experimente mit Injektionen von Metallen (Gold, Silber, Glas, Eisen, Kupfer, Quecksilber, Blei), organischen und anorganischen Substanzen, wie Gummi Guttae, Crotonöl, Terpentinöl, Cantharidin, Thiodiglycolchlorid, Jerquiritin, Indigo, Harnsäure, Öl, Stärke, tierischem Gewebe, arseniger Säure und von Bestandteilen von Mikroorganismen, wie Schimmel- oder Spaltpilzen durch.

13 Es wurden zum Beispiel aus Heft 8 die Versuche 25, 26 (Golddraht) und 17 (Silberdraht) von 1880, aus Heft 9 (Röhrchen mit Gold in vorderer Kammer) und Heft 10 (Goldstaub in vorderer Kammer) einzelne Versuche übernommen (Leber 1891: 396-411).

14 Vgl. beipielsweise: Heft 15 Versuch 21 (1884) über die Injektion von Platinschwarz in die vordere Augenkammer am 7.6.1884: „Also der Befund ganz derselbe, wie bei der Zinnober- oder Goldinjection. Da wo das Pt [Platin] der Iris aufliegt, entsteht ein leichter Fibrinbelag, das Gewebe färbt sich intensiver mit Haematoxylin, es tritt Einwanderung von Lymphkörperchen auf, welche die Körnchen aufnehmen. Ein wahrscheinlicher Unterschied gegenüber der Gold- oder Zinnoberinjection ist aber nicht vorhanden. Die besonders starke Wirkung in diesem Fall kann durch die ungewöhnlich reichliche Menge des Pulvers bedingt gewesen sein. In den anderen Fällen war die Reizwirkung eher geringer als bei Gold."

15 Heft 10: 24.9.83 Gabe von reinem Goldstaub in die vordere Kammer; Heft 9: 13.10 .83 Goldstaub im Röhrchen verglichen mit leeren Glasröhrchen; Heft 5: 1.11.83 Goldstaub in die vordere Kammer; Heft 2: 15.11 .83 Goldstaub unter die Konjunktiva und Heft 6: Goldstaub in die Kornea. Gold wurde in der Medizin häufig als Nahtmaterial verwendet.

16 Vgl. Heft 12 (1890) Versuch XVII: „Injection v. chem. rein, sterilis. schwefels. Baryt in $3 / 4 \%$ $\mathrm{NaCl}$-lösg. suspendiert in die v. Kammer v. Kaninchen. D. schwefelsaure Baryt wurde aus chem. rein. Substanzen dargestellt v. Dr. Münder u. vollk. rein ausgewaschen, dann geglüht. [...] Bei allen Versuchen (XVII-XIX) wird die mittelfeine Stichcanüle v. oben her bei luxiertem Bulbus (mit Cocain) durch den Scleralrand u. von hinten durch die Iris durchstochen."

17 Vgl. Heft 7 über die Einführung von Glas und Glaspulver in die vordere Augenkammer und den Glaskörper mit Leber 1891: 208-219.

18 Er führte wahrscheinlich nur die makro- und mikroskopischen Beobachtungen selbst durch; die Vorbereitung des Versuchstieres und die Injektion des Fremdmaterials nahmen Mitarbeiter aus seinem Labor vor; vgl. Heft 5 Vers. LXX (1883) am 20.5.1890: „An der Hornhaut ist keine Narbe, doch scheint d. Unterbrechung d. M. Desc. zu beweisen, daß ein Trauma stattgefunden hat. Vielleicht wurde in d. Falle die Injection am unter. Hornhautrand gemacht!“ und Heft 9 Vers. LI von 1883 am 16.10.83: „Einführung eines mit chem. rein. Goldstaub gefüllten Röhrchens in die vordere Kammer (vermuthlich gepulvertes Blattgold, was nachträglich durch die mikr. Untersuchung des aufbewahrten, später noch zu Vers. LXXXII benutzten Röhrchens bestätigt wird).“

19 Weitere Skizzen finden sich in Heft 5 Versuche LVIII-LXIII (1883); Heft 6 Versuch 148 (1886); Heft 8 Versuch 54 (1887), Versuch 25 (1880) und Versuch XXXVI a u. b (1879); Heft 9 Fortsetzung Versuch XXVI b; Heft 16 Versuch XXXIX (1879). 
20 Leber untersuchte 1886 wegen einer Publikation und dann 1890 in einer ausführlichen histologischen Untersuchung ein aufbewahrtes Augenpräparat von 1883; vgl. Heft 5 Vers. LXI (1883) am 8.11.86: „Das bisher in Müll. Fl. gut conservierte Auge wird (??) diese Tage cursorisch untersucht, um zu sehen, ob vielleicht an der Iris od. der Corneoscleralgrenze von Gewebe eine Spur auf Lösung von Spuren von Gold hinweisende Färbung zu finden wäre, [...] aber auch hier von Gewebe nichts von Tinction wie bei den (?) Beobachtungen von den Silberarbeitern." und Blaschko 1886: 651-656.

21 Vgl. Heft 1 (1897) Versuche über die Injektion von kohlen- und phosphorsaurem Kalk in die Bindehaut und vordere Kammer und Heft 13 (1892) Versuche über die Injektion von Ultramarin in die vordere Kammer.

22 Vgl. Heft 1 Vers. XII (1897) am 11.11.1897: „D. Gewebe durchsichtiger; die Schollen streifig, machen jetzt ganz den Eindruck amyloider Degeneration. [...] die Bilder haben die größte Ähnlichkeit mit denen bei der Coniunctivitis petrificans." Vgl. auch Heft 13 Vers. 12 von 1892 am 9.5.1892: „Es soll geprüft werden, ob auch andere sehr fein vertheilte indifferente Substanzen b. Injection in d. v. Kammer in reichlicher Menge Spontanperforation am Hornhautrand bewirken."

23 Heft 8 Vers. 17 (1880) am 27.7.89; das „+“" steht in den Protokollen für „mit“.

24 Vgl. z. B.. Heft 8 Vers. 25 (1880) am 21.6.89: „sonst ähnlich aussehend wie Vers. 17, wo aber die Körnchen in glatten Zellen lagen." und Heft 8 Vers. 17 von 1880 am 27.7.89: „Ganz anders als b. Vers. 25. Hier fehlt (?) Seite die Stäbchenschicht auf d. ganzen Pap.d.messer, die ä. K.-Sch. fehlt so weit, an d. Grenze zwei getrennte niedrige Tafeln als Rudiment, die i. K.-Sch. auch s. dünn, d. Molecular- u. Ganglienschicht geschwunden.“; „K.-Sch.“ steht für „Körnerschicht“. Der Versuch XXXV b aus Heft 7 (1879) war als Vergleich angelegt. Dabei wurde der Teilversuch XXXV a vom 4.VIII.89 erneut beurteilt: „Bei ${ }^{\text {mehrfach }}$ wiederholter Untersuchung des Pigments erhält man doch den Eindruck, daß die Retina od. bes. das Pigmentepithel pathologisch verändert ist."

25 Vgl. Heft 5 Versuche LXV-LXXII (1883) über Injektion von Goldstaub in die vordere Augenkammer: „Da bei der vorigen Versuchsreihe der Goldstaub bei nachträgl. mikr. Untersuchung nicht vollst. chem. rein gefunden wurde, (vgl. Vers. LX) wird eine neue Versuchsreihe aufgestellt, in etwas (?) Weise."

26 Vgl. Heft 8 Versuch XXXVI b (1879) unter der Überschrift Gold im Glaskörper und später unter der Überschrift Silber im Glaskörper Versuch XXXVI a und b.

27 Vgl. Heft 5 Versuch LX von 1883 über die Injekion von Goldstaub in die vordere Augenkammer am 2.11.83.

28 Heft 10 (1883) über die Einführung von Goldstaub in vorderer Kammer vgl. Leber: 1891: 396-400; Heft 9 (1883) über die Einführung von Röhrchen mit Gold in die vordere Augenkammer vgl. Leber 1891: 400-402; Heft 4 Versuche 134 und 135 und Heft 6 Versuch 148 (1886) über die Einführung von Schaumgold in die Cornea vgl. Leber 1891: 403; Heft 15 (1884) über die Einführung von Platinschwarz in die vordere Augenkammer vgl. Leber 1891: 405; Heft 14 (1890) über die Einführung von Kieselsäure in die vordere Augenkammer vgl. Leber 1891: 408-411.

29 Vgl. Heft 7 Forts. v. Vers. XXXV b (1879) am 16.12.80 mit Leber 1891: 209.

\section{Literatur}

Anonym 1917. Obituary, 1917. Theodor Leber (1840-1917). The British Journal of Ophthalmology (1): 648-652.

Blaschko, Alfred 1886. Ueber physiologische Versilberung des elastischen Gewebes. Archiv für mikroskopische Anatomie (27): 651-656.

Blum, Marcus, Philip Hykin, Melinda Sanders und Hans Völcker 1992. Theodor Leber: A Founder of Ophthalmic Research. Survey of Opthalmology (37): 63-68.

Canguilhem, Georges 1979. Der Beitrag der Bakteriologie zum Untergang der „medizinischen Theorien" im 19. Jahrhundert. In: Wolf Lepenies (Hg.). Wissenschaftsgeschichte und Epistemologie. Gesammelte Aufsätze. Frankfurt am Main: Suhrkamp: 110-133. 
Cohnheim, Julius 1914. Über Entzündung und Eiterung. Leipzig: Johann Ambrosius Bart.

Cunningham, Andrew und Perry Williams (Hg.) 1992. The Laboratory Revolution in Medicine. Cambridge: Cambridge University.

Czaplewski, Eugen 1892. Weitere Untersuchungen über die Immunität der Tauben gegen Milzbrand. Zeitschrift für Hygiene und Infektionskrankheiten (12): 348-474.

Fleck, Ludwig 1980 [1935]. Entstehung und Entwicklung einer wissenschaftlichen Tatsache. Einführung in die Lehre vom Denkstil und Denkkollektiv. Frankfurt am Main: Suhrkamp.

Flügge, Carl 1888. Studien über die Abschwächung virulenter Bacterien und die erworbene Immunität. Zeitschrift für Hygiene (4): 208-230.

Gabritschewsky, Georg 1900. Ueber active Beweglichkeit der Bakterien. Zeitschrift für Hygiene und Infektionskrankheiten (35): 104-122.

Gradmann, Christoph 2005. Krankheit im Labor. Robert Koch und die medizinische Bakteriologie. Göttingen: Wallstein.

Grawitz, Paul und Wilhelm de Bary 1887. Ueber die Ursachen der subcutanen Entzündung. Archiv für pathologische Anatomie und Physiologie (108): 67-102.

Hacking, Ian 1983. Representing and Intervening. Introductory in Philosophy of Natural Science. Cambridge: Cambridge University.

Heesen, Anke te und Emma Spary (Hg.) 2001. Sammeln als Wissen: Das Sammeln und seine wissenschaftsgeschichtlichen Bedeutung. Göttingen: Wallstein.

Hess, Volker und Andrew Mendelsohn 2010. Case and Series: Medical Knowledge and Paper Technology, 1600-1900. History of Science (48): 287-314.

Hess, Volker und Andrew Mendelsohn 2013. Paper Technology und Wissensgeschichte. NTM Zeitschrift für Geschichte der Wissenschaften, Technik und Medizin (21): 1-10.

Hertwig, Oskar 1923. Allgemeine Biologie. Jena: Gustav Fischer.

Hoffmann, Christoph 2008. Daten sichern. Schreiben und Zeichnen als Verfahren der Aufzeichnung. Zürich/Berlin: Diaphanes.

Holmes, Frederic, Jürgen Renn und Hans-Jörg Rheinberger (Hg.) 2003. Reworking the Bench. Research Notebooks in the History of Science. Dordrecht: Kluwer Academic Publishers.

Jäger, Wolfgang 1985. Theodor Leber und die Begründung der experimentellen Ophthalmologie. In: Wilhelm Doerr und Peter Riedl (Hg.). Semper Apertus. 600 Jahre Ruprecht-KarlsUniversität Heidelberg 1386-1986. Heidelberg: Springer: 321-331.

Jäger, Wolfgang 1988. The Foundation of Experimental Ophthalmology by Theodor Leber. Documenta Ophthalmologica (68): 71-77.

Kaposi, Moriz 1892. Ueber die Behandlung der tuberculösen Haut- und Schleimhautaffectionen mit Tuberculin. Archiv für Dermatologie und Syphilis (24): 10-53.

Karg, Karl 1887. Ein Beitrag zur Lehre von der Entzündung und der Regeneration. Deutsche Zeitschrift für Chirurgie (25): 323-336.

Kästner, Hermann 1924: Beiträge zur neuropathologischen Entzündungslehre und zur Lehre von der Chemotaxis. Zeitschrift für die gesamte experimentelle Medizin (43): 479-516.

Kisskalt, Karl 1903. Beiträge zur Lehre von der natürlichen Immunität. Zeitschrift für Hygiene und Infektionskrankheiten (45): 1-60.

Latour, Bruno und Steve Woolgar 1986. Laboratory Life. The Construction of Scientific Facts. Princeton: Princeton University.

Latour, Bruno 1990. Drawing Things together. In: Micheal Lynch und Steve Woolgar (Hg.). Representation in Scientific Practice. London: Kluwer: 19-68.

Leber, Theodor 1879. Keratomycosis aspergillina als Ursache von Hypopyonkeratitis. Albrecht von Graefes Archiv für Ophthalmologie (25): 285-301.

Leber, Theodor 1884. Beobachtungen über die Wirkung ins Auge eingedrungener Metallsplitter. Albrecht von Graefes Archiv für Ophthalmologie (30): 243-258.

Leber, Theodor 1888. Ueber die Entstehung der Entzündung und die Wirkung der entzündungserregenden Schädlichkeiten. Fortschritte der Medizin FdM-Internationale Zeitschrift für die gesamte Heilkunde (15): 460-464.

Leber, Theodor 1889. Die Bedeutung der Bacteriologie in der Augenheilkunde. In: Hermann Knapp und Carl Schweigger (Hg.). Archiv für Augenheilkunde. Wiesbaden: J.F. Bergemann: 192-194.

Leber, Theodor 1891. Die Entstehung der Entzuendung und die Wirkung der entzuendungserregenden Schaedlichkeiten nach vorzugsweise an Auge angestellten Untersuchungen. Leipzig: Wilhelm Engelmann. 
Leber, Theodor 1891. The Origin of Inflammation. The Lancet (137): 1328-1329; 1446-1448.

Mac Cormac, William 1881. Transactions of the International Medical Congress Seventh Session. London: K.W. Kolckmann.

Marchand, Felix 1921. Über den Entzündungsbegriff. Archiv für pathologische Anatomie und Physiologie und für klinische Medizin (234): 245-299.

McCutcheon, Morton 1946. Chemotaxis in Leucocytes. Physiological Reviews (26): 319-336.

Metschnikoff, Elias 1883. Untersuchungen über die intrazelluläre Verdauung bei wirbellosen Thieren. Arbeiten aus dem Zoologischen Institut der Universität Wien und der Zoologischen Station in Triest: $1-28$.

Metschnikoff, Elias 1884. Ueber eine Sprosspilzkrankheit der Daphnien. Beitrag zur Lehre über den Kampf der Phagocyten gegen Krankheitserreger. Archiv für pathologische Anatomie und Physiologie und für klinische Medicin (96): 177-195.

Rheinberger, Hans-Jörg und Michael Hagner (Hg.) 1993. Die Experimentalisierung des Lebens. Experimentalsysteme in den biologischen Wissenschaften 1850/1950. Berlin: Akademie.

Rheinberger, Hans-Jörg 2001. Experimentalsysteme und epistemische Dinge. Eine Geschichte der Proteinsynthese im Reagenzglas. Göttingen: Wallstein.

Rheinberger, Hans-Jörg 2005. Kritzel und Schnipsel. In: Bernhard Dotzler und Sigrid Weigl (Hg.). "fülle der combination". Literaturforschung und Wissenschaftsgeschichte. München: Wilhelm Fink: $343-356$.

Sarasin, Philipp 2001. Reizbare Maschinen. Eine Geschichte des Körpers 1765-1914. Frankfurt am Main: Suhrkamp.

Schlich, Thomas 1996. Die Konstruktion der notwendigen Krankheitsursache: Wie die Medizin Krankheit beherrschen will. In: Cornelius Borck (Hg.). Anatomien medizinischen Wissens. Medizin-Macht-Moleküle. Frankfurt am Main: Fischer: 201-229.

Silverstein, Arthur 2008. History of Immunology. London: Elsevier.

Soyka, Isidor 1878. Die Naegeli'sche Theorie der Infectionskrankheiten in ihren Beziehungen zur medicinischen Erfahrung. Archiv für experimentelle Pathologie und Pharmakologie (9): 131132.

Jin, Tian, Xuehua Xu und Dale Hereld 2008. Chemotaxis, Chemokine Receptors and Human Disease. Cytokine (44): 1-8.

Tückermann, August 1892. Ueber die Vorgänge bei der Resorption in die vordere Kammer injicierter körniger Farbstoffe. Albrecht von Graefes Archiv für Ophthalmologie (38): 60-92.

Vicker, Michael, John Lackie und Walter Schill 1986. Neutrophil Leucocyte Chemotaxis is not Induced by Spatial Gradient of Chemoatractant. Journal of Cell Science (84): 263-280.

Wagenmann, August 1917. Theodor Leber. Albrecht von Graefes Archiv für Ophthalmologie (93): II-VIII.

Wahrig-Schmidt, Bettina 1994. Das "geistige Auge“ des Beobachters und die Bewegung der vorherrschenden Gedankendinge. Beobachtungen an Beobachtungen von Zellen in Bewegung zwischen 1860 und 1885. In: Micheal Hagner, Hans-Jörg Rheinberger und Bettina Wahrig-Schmidt (Hg.). Objekte, Differenzen und Konjunkturen. Experimentalsysteme im historischen Kontext. Berlin: Akademie: 23-48.

Wells, Harry Gideon 1920. Chemical Pathology. Being a Discussion of General Pathology from the Standpoint of the Chemical Processes Involved. Philadelphia: W. B. Saunders.

Dorina Stahl

Institut für Medizingeschichte und

Wissenschaftsforschung der Universität zu

Lübeck

Königstrasse 42

23552 Lübeck

Germany

E-Mail: dorinastahl@gmx.de 